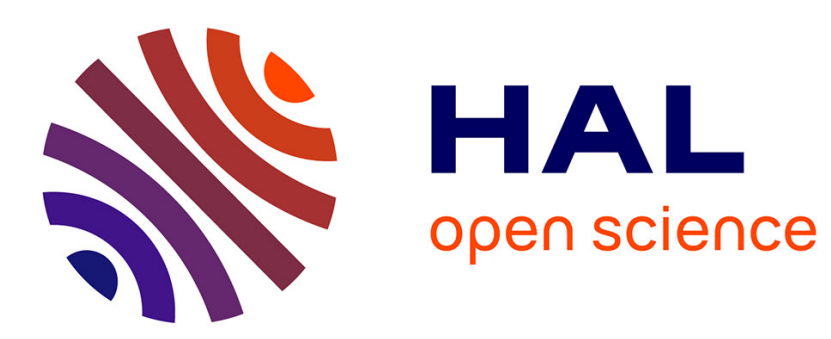

\title{
Direct ENSO impact on East Asian summer precipitation in the developing summer
}

Na Wen, Zhengyu Liu, Laurent Li

\section{To cite this version:}

Na Wen, Zhengyu Liu, Laurent Li. Direct ENSO impact on East Asian summer precipitation in the developing summer. Climate Dynamics, 2019, 52 (11), pp.6799-6815. 10.1007/s00382-018-4545-0 . hal-02440104

\section{HAL Id: hal-02440104 \\ https://hal.science/hal-02440104}

Submitted on 15 Jan 2020

HAL is a multi-disciplinary open access archive for the deposit and dissemination of scientific research documents, whether they are published or not. The documents may come from teaching and research institutions in France or abroad, or from public or private research centers.
L'archive ouverte pluridisciplinaire HAL, est destinée au dépôt et à la diffusion de documents scientifiques de niveau recherche, publiés ou non, émanant des établissements d'enseignement et de recherche français ou étrangers, des laboratoires publics ou privés. 


\section{Direct ENSO impact on East Asian summer precipitation in the}

\section{developing summer}

\author{
Na WEN ${ }^{1}$, Zhengyu LIU ${ }^{2}$, Laurent $\mathrm{Li}^{3}$,
}

1.Key Laboratory of Meterorological Disaster of Ministry of Education and College of Atmospheric

Sciences, Nanjing University of Information Science \& Technology, Nanjing, China

2. Atmospheric Science Program, Department of Geography, Ohio State University

3. Laboratoire de Meteorologie Dynamique, CNRS, Sorbonne Université, Paris, France

7 Corresponding author address:

8 Dr. Na Wen, College of Atmospheric Science, Nanjing University of Information Science \&

9 Technology, Nanjing 210044, China, E-mail: wenna@nuist.edu.cn 
Abstract: In the developing stage of ENSO, the East Asia summer precipitation (EASP) shows a large variability that is significantly different from that in the decaying summer. In this study, we will focus on understanding the direct El Niño impact on the precipitation over East Asia in the developing summer in the observation. It is found that in its developing summer, the El Niño sea surface temperature anomaly affects the EASP directly from the eastern-central tropical Pacific, with little interference from the rest of the global ocean. The corresponding precipitation anomaly exhibits a tri-pole pattern, with two positive nodes in northeast and southeast China, sandwiched by a negative node in northern/central China. The tri-pole precipitation response is mainly attributed to the El Niño-induced cyclonic anomaly in Northeast Asia and the anticyclonic anomaly in the western North Pacific, which are part of the circulation anomalies of a circumglobal wave teleconnection in the subtropical jet in the Northern Hemisphere and a low-level meridional wave train along East Asia coast. These circulation anomalies are generated by the summer El Niño in three pathways: (1) the vertical motion-induced perturbation over the central-eastern tropical Pacific entering into the subtropical jet excites a circumglobal wave train propagation eastward along the jet; (2) the El Niño-induced dipole heating across the equatorial Maritime Continent is mainly responsible for the meridional wave propagation along East Asia coast; (3) the El Niño-induced indirect heating over Northwest India triggers another perturbation in the jet waveguide, all contributing to the precipitation variation in East Asia. Further demonstration indicates the atmospheric response to the El Niño direct heating and perturbation over the tropical Pacific has the major contribution to the El Niño-induced circulation anomaly. As to the El Niño indirect heating over Northwest India, a zonal wave train response in the upper midlatitude which is mainly confined in the Eurasia sector makes a competing contribution to the circulation anomaly over East Asia.

Key words: Direct impact of El Niño, East Asian Summer Precipitation, Developing stage summer, Physical Mechanisms of El Niño impact 


\section{Introduction}

El Niño ${ }^{1}$ is the most prominent climate variability in the tropical Pacific. Due to the phase-locking of its peak SST anomaly to boreal winter, El Niño SST anomaly usually undergoes a developing stage and a decaying stage in the preceding and following summers, respectively. Since the early 1980s, it has been noticed that the relationships between El Niño and the East Asian Summer Monsoon differ in different stages of ENSO (Fu 1987; Huang and Wu 1989; Liu and Ding 1992; Zhang et al. 1996). Most studies, however, have focused on the El Niño influence on East Asia summer precipitation (EASP) in the following summer, due to its great influence on the Mei-yu rainfall after El Niño and the precursor role of the sea surface temperature (SST) anomaly in winter providing a convenient predictor for EASP in the following summer. These studies seem to converge on the conclusion that, in the decay stage of El Niño, the climate impact of El Niño on East Asian monsoon in the following summer has to be produced indirectly through the El Niño-induced SST anomalies outside the tropical Pacific. For instance, the local air-sea coupling over the western North Pacific (WNP) maintains the anomalous Philippine Sea anticyclone to the ensuing summer and then conveys the impact of El Niño to the East Asian summer monsoon; the El Niño-induced tropical Indian Ocean SST anomaly persistent to the following summer feeds back on the atmosphere and extends the winter El Niño effect into the following summer (Wang and Zhang 2002; Yang et al. 2007; Xie et al. 2009; Wu et al. 2012).

In comparison with the El Niño influence on the EASP in the following summer, the impact of El Niño on the EASP in the developing summer has been more controversial. Huang and $\mathrm{Wu}(1989)$ found that in the developing summer of El Niño, the Yangtze River and Huaihe Valleys are anomalously wet, while North and South China experience anomalously dry. It is hypothesized that the cold SST in the western tropical Pacific suppresses the atmospheric convection over South Asia, resulting in a southward shift of the subtropical high in the WNP and, in turn, abundant rainfall in

\footnotetext{
${ }^{1}$ In this paper, unless otherwise specified, El Niño refers to both its warm and cold phase.
} 
the Yangtze-Huaihe River Valley. Zhang et al. $(1999,2001)$ attributed the deficient rain over South China and abundant rain over the Yangtze-Huaihe Valley to the westward intensification of the western Pacific subtropical high, and the anomalous dryness over the northern part of China is due to the reduced moisture transport by the weakened Indian monsoon. Wu et al. (2003) related the East Asian precipitation anomaly with the evolution of ENSO, using the extended singular value decomposition (SVD) method. Their result indicates that in the El Niño developing summer, the major feature of the precipitation anomaly over East Asia is the negative precipitation over western North China, which is associated with an anomalous cyclone over East Asia. Wu et al. (2009) did similar analysis but using a season-dependent empirical orthogonal function (S-EOF) analysis. Their result revealed an increase of rainfall over southeastern China in El Niño-developing summer, which is associated with an intense cyclonic anomaly over the intertropical WNP and an anticyclone over the northern Indian Ocean. These controversial results motivate us to perform a comprehensive study on the relation between the EASP and ENSO in the developing summer.

Furthermore, from the perspective of atmospheric dynamics, previous works have suggested some teleconnection patterns in boreal summer that impact East Asian climate, with implicit relationship with ENSO. Statistically, Kripalani and Kulkarni (1997, 2001) found that the all Indian rainfall has a robust in-phase correlation with the rainfall over North China but an out-of-phase relation over South Japan. Wu (2002) furthermore pointed out that it is the mid-latitude Asian summer (MAS) pattern that is featured as barotropic anticyclones northwest of the Tibetan Plateau and over Northeast China, connecting the Indian summer monsoon with the East Asian monsoon. Hu et al. (2004) attempted to separate the internal variability of Indian rainfall influence on the atmosphere from that caused externally by ENSO. Their result indicated that the variability independent of Indian rainfall is connected to the zonal propagation over the mid-latitude Asian continent, while the variability related to ENSO prefers to propagate meridionally: one over the East Asian continent, and the other over the western Pacific Ocean. Covering the MAS pattern over the Eurasia 
continent, also termed as the "Asian continent pattern" (Krishman and Sugi, 2001) or the "silk-road pattern" (Enomoto et al., 2003), Ding and Wang (2005) expanded the summer teleconnection around the globe, naming it as the Circumglobal Teleconnetion (CGT) pattern. The CGT exhibits six prominent 'centers of action' over western Europe ('+'), European Russia('-'), west-central Asia('+'), east Asia('+'), the North Pacific('+'), and North America('+'), with the sign '+/-' in the bracket indicating the phase relation. Two mechanisms have been proposed for the generation of a CGT teleconnection. One is the abnormal Indian summer monsoon rainfall, which may excite an anomalous wave train over the Eurasia extending downstream to the North Pacific and North America. The other is the wave train excited in the jet region of the North Atlantic which may affect the western-central Asian High and thus the intensity of the ISM. Further investigation of Ding et al. (2011) indicated that the first leading SVD mode of the Northern hemisphere 200hPa geopotential height and the tropical rainfall in summer involves CGT pattern in midlatitude, and appears preferentially in the summer preceding the peak phase of ENSO. They suggested that ENSO forces a zonally symmetric response in the tropics and extratropics, while ENSO-related India summer monsoon is mainly responsible for the wave component of CGT.

In addition to the zonal teleconnection pattern in boreal summer, there is also a prominent feature of meridional propagation of Rossby wave over the western North Pacific, known as the Pacific-Japan (PJ) pattern by Nitta (1987). This PJ pattern has a significant influence on the climate in Japan through its impact on the subtropical Bonin High. Kosaka and Nakamura (2010a) further performed a dynamical analysis of the meridional dipole mode excited by the convection anomaly near the Philippines in the context of East Asian summer monsoon. They suggested that the PJ pattern can be regarded as a moist dynamical mode, which sustains itself via both dry energy conversion and the interaction with moisture process. Their study also identified another prominent meridional teleconnection pattern, which is slightly eastward of the PJ pattern with a quarter phase shift in the meridional direction, and is likely related with the tropical SST anomaly in the developing summer of ENSO. The 
aforementioned teleconnection either focused on the zonal propagation pattern or meridional pattern, both of which seem to be related to the ENSO in the developing stage. One question addressed here is therefore whether these teleconnections occurred coherently or occurred independent from each other. If they are related, how are they organized coherently by El Niño?

Recently, in studying the direct impact of SST on the atmosphere, Wen et al. (2015) identified a robust climate response over East Asia to summer El Niño-pattern SST anomaly using the Generalized Equilibrium Feedback Assessment (GEFA). Their GEFA analysis implied a potential role of the El Niño SST anomaly forcing on EASP from the tropical Pacific in the developing summer of ENSO, because one of their SST forcing factors is dominated by the summer El Niño SST anomaly in the equatorial Pacific. The GEFA analysis, however, does not show the direct summer response explicitly from the time evolution perspective and therefore does not address the direct response in summer. As a follow-up research, this study will further investigate the relation between EASP and the El Niño SST anomaly in developing summer from the time evolution perspective using the composite analysis. We explicitly demonstrate that in the developing summer, the El Niño SST anomaly in the eastern-central tropical Pacific is the direct forcing factor on the EASP. The corresponding precipitation anomaly exhibits a tri-pole pattern, with an anomalous wetness in northeastern and southern China and an anomalous dryness in northern/central China. The tri-pole precipitation response is attributed mainly to the El Niño-induced cyclonic anomaly in Northeast Asia and the anticyclonic anomaly in the WNP. Furthermore, this study identifies three possible atmospheric teleconnections that enable the El Niño SST in the tropical Pacific to affect East Asia in summer: the zonal wave train across the globe (CGT), the meridional wave propagation along the East Asia coast $(\mathrm{PJ})$ and wave guide triggered by the indirect heating from Northwest India. The paper is organized as follows. The data and method are described in Section 2. The direct impact of El Niño on the EASP in its developing stage and its associated circulation anomaly are documented in Section 3. Possible mechanisms of El Niño influence on the circulation are examined in Section 
4. Further analysis of the atmospheric response to El Niño-induced direct / indirect heating is given in Section 5. A summary and discussion are given in Section 5.

\section{Data and method}

The monthly precipitation data are from 160 stations covering mainland China during the period of 1958 to 2012, which is provided by the Chinese Meteorological Data Center, CMA. The domain for investigation is east of 100E, with 140 evenly distributed stations. To reduce the noise, the data is reconstructed by using the first leading 10 empirical orthogonal function (EOF) modes, which retains about 60 percent of the total variance. Main conclusions remain unchanged when the original rainfall data are used. The precipitation variability is represented by the precipitation percentage, which is defined as the ratio of the precipitation anomaly to its seasonal climatological mean at each station. In addition to the regional precipitation data over East China, we also used the NOAA monthly precipitation reconstruction data (PREC) (Chen et al. 2004) and land precipitation data compiled by the Climatic Research Unit (CRU) (Michell and Jones 2005) in the same period (1958-2012) for the investigation of El Niño-induced heating at global scale. Furthermore, the combined precipitation data (GPCP) (Adler et al. 2003) and NOAA interpolated outgoing long-wave radiation (OLR) in a short period (1979-2012) are also used for consistent check. Other data used in this study includes monthly means of multiple variables from the National Centers for Environmental Prediction National Center for Atmospheric Research (NCEP-NCAR) reanalysis data from 1958 to 2012 (Kalnay et al. 1996). Variables include sea surface temperature, air temperature at $850 \mathrm{hPa}$, vertical velocity at $500 \mathrm{hPa}$, wind at $850 \mathrm{hPa}$ and $500 \mathrm{hPa}$, and geopotential height at $850 \mathrm{hPa}, 500 \mathrm{hPa}$ and $200 \mathrm{hPa}$. Anomalies of all variables are defined as the deviations from the mean seasonal cycle, with the long-term trend removed by a third-order polynomial filter. Regional analysis across East Asia is performed using the reanalysis on the original grid $\left(2.5^{\circ} \mathrm{X} 2.5^{\circ}\right)$, while the global analysis is performed using a low-resolution version $\left(7.5^{\circ} \mathrm{X} 7.5^{\circ}\right)$ to reduce the spatial noise. 
We mainly focus on the impact of El Niño on EASP in its developing stage.

Physically, the time scale of the atmospheric response to underlying tropical SST forcing is within a few months (e.g. Gill 1980; Hoskins and Karoly 1981; Peng and Whitaker 1995; Li and Conil 2003; Liu and Alexander 2007). Any direct response of the East Asian summer monsoon to El Niño should be determined largely by the SST anomaly concurring in the same summer. Therefore, a summer El Niño index is employed for composite analysis in this study.

Summer is represented by the three-month mean of June, July and August (JJA). During the period of 1958 to 2012, a total of 36 El Niño/La Niña events are identified, according to the generally-accepted criterion that the three-month running mean SST anomalies in Nino-3.4 region $\left(5^{\circ} \mathrm{S}-5^{\circ} \mathrm{N}, 120^{\circ}-170^{\circ} \mathrm{W}\right)$ exceeds the threshold of $+/-0.5{ }^{\circ} \mathrm{C}$ for a minimum of 5 consecutive over-lapping seasons (http://www.cpc.ncep.noaa.gov/products/analysis_monitoring/ensostuff/ensoyears.sht $\mathrm{ml})$. When the Nino-3 or Nino-3.4 SST anomaly in $\mathrm{JJA}(0)$ is above/below $+/-0.5^{\circ} \mathrm{C}$, it is defined as a strong summer El Niño/La Niña case in the developing stage, with the exception of the 1998/1999 event because of an out-of-phase SST anomaly between Nino-3 and Nino-3.4 region. As shown in Fig. 1, 24 strong summer ENSO cases are selected with 11 El Niño events and 13 La Niña events. However, due to the complexity of the evolution of ENSO, La Niña often lasts a longer time than El Niño does, such as 1970-1972, 1973-1976 and 1998-2001. To avoid the mixture of the developing and decaying years for La Niña, the four events of 1971/1972, 1974/1975, 1975/1976 and 2000/2001 are excluded. The final composite analysis is obtained with the 11 warm and 9 cold events (warm minus cold, and then divided by 2). The significance of the results is examined using a Monte Carlo method, in which the so-called 'warm' and 'cold' phases of ENSO are randomly scrambled among the 20 summer ENSO events by 1000 times, effectively equivalent to the student " $t$ " test (Wen et al. 2016). Notice that, when the four La Niña events are included, the results show little change from that presented here. In addition, we also did the high-pass filter analysis with the variability above 8-year periods removed, and the results 
remain qualitatively unchanged.

To evaluate the wave energy propagation in a zonally asymmetric climatological mean flow, the wave activity flux defined by Takaya and Nakamura (2001) is used. The formula of its horizontal component in spherical coordinates is in the following,

$$
W=\frac{p \cos \phi}{2|\bar{U}|}\left(\begin{array}{c}
\frac{\bar{u}}{a^{2} \cos ^{2} \phi}\left[\left(\frac{\partial \varphi^{\prime}}{\partial \lambda}\right)^{2}-\varphi^{\prime} \frac{\partial^{2} \varphi^{\prime}}{\partial \lambda^{2}}\right]+\frac{\bar{v}}{a^{2} \cos \phi}\left[\frac{\partial \varphi^{\prime}}{\partial \lambda} \frac{\partial \varphi^{\prime}}{\partial \phi}-\varphi^{\prime} \frac{\partial^{2} \varphi^{\prime}}{\partial \lambda \partial \phi}\right] \\
\frac{\bar{u}}{a^{2} \cos \phi}\left[\frac{\partial \varphi^{\prime}}{\partial \lambda} \frac{\partial \varphi^{\prime}}{\partial \phi}-\varphi^{\prime} \frac{\partial^{2} \varphi^{\prime}}{\partial \lambda \partial \phi}\right]+\frac{\bar{v}}{a^{2}}\left[\left(\frac{\partial \varphi^{\prime}}{\partial \phi}\right)^{2}-\varphi^{\prime} \frac{\partial^{2} \varphi^{\prime}}{\partial^{2} \phi}\right]
\end{array}\right)
$$

where $\varphi$ denotes the stream function, $(u, v)$ is the horizontal velocity, and $a, \lambda, \phi$ are the radius of the earth, and the latitude and longitude, respectively, with $p$ for the pressure level. Overbar and prime represent climatology mean and deviation. The flux is independent of wave phase and equals to the group velocity of the stationary Rossby wave in the WKB sense. Therefore, the calculation result for the composite based on summer El Niño index could be regarded as the stationary Rossby wave embedded in the mean flow. In addition, to reduce the spatial noise, a spherical harmonic analysis is applied in the low level $850 \mathrm{hPa}$, where the $95 \%$ information is maintained.

To separate the atmospheric response to El Niño-induced direct heating over the tropical Indo-Pacific and indirect heating over Northwest India, a partial regression is used. In practice, to assess the atmospheric response to El Niño-induced direct heating, we first remove the information of the heating variability over Northwest India. We then perform the regression of the residual atmosphere on the residual heating time series. It is the same as the partial regression on the indirect heating over Northwest India. The direct heating index of El Niño is defined by the normalized principle component of the first leading EOF mode of the PREC precipitation over the region $\left(70^{\circ} \mathrm{E} \sim 80^{\circ} \mathrm{W}, 20^{\circ} \mathrm{S} \sim 10^{\circ} \mathrm{N}\right)$. The indirect heating index over Northwest India is derived from the domain average for the PREC 
precipitation over the region $\left(60^{\circ} \mathrm{E} \sim 88^{\circ} \mathrm{E}, 15^{\circ} \mathrm{N} \sim 35^{\circ} \mathrm{N}\right)$, normalized by its standard deviation.

\section{Direct Impact of EI Niño on East Asian Summer Precipitation in}

\section{its Developing Summer}

The response of EASP differs significantly between the developing stage of El Niño and the decaying stage. This difference can be seen clearly in the Hovmöller diagram Fig. 2b, which shows the composite anomalous precipitation zonally averaged over East Asia for all El Niño events (as shown in Fig. 2a) from the preceding to the following year as a function of latitude. It's clearly seen that El Niño has a significant impact on the EASP, especially in summer when a large portion of the annual precipitation is concentrated (contours in Fig. 2b). In the developing summer, El Niño forces abundant rainfall in southern China and a deficiency of rain in northern China, while, in the decaying stage, the rainfall anomaly pattern is almost the opposite to that of the developing stage, with a slight northward or southward shift of the anomaly centers. This sharp contrast of EASP response between the developing and decaying stages of El Niño is consistent with early findings (Fu 1987; Huang and forced directly by the sea surface temperature (SST) anomalies concurring in the summer, due to the rapidity of atmospheric response to SST forcings (within a few months) (e.g. Hoskins and Karoly 1981; Peng and Whitaker 1995; Li and Conil 2003). In the decay stage of El Niño, SST anomaly in the eastern-central equatorial Pacific diminishes (thick black line in Fig. 2a). The impact of El Niño on the East Asian monsoon in the following summer should be produced indirectly through the El Niño-induced SST anomalies in other oceans as indicated by previous studies (Wang and Zhang 2002; Yang et al. 2007; Xie et al. 2009). In contrast to the diminishing SST anomaly in the decaying summer, the SST anomalies in the eastern-central tropical Pacific in most cases are already well established in the developing summer of El Niño. As shown in Fig. 2a, the averaged SST anomaly over the Nino3.4 region is 
around $0.6^{\circ} \mathrm{C}$ in July, which is half of the peak amplitude in winter. The asymmetric behaviors of the El Niño SST anomalies between the developing and decaying stages indicate that the direct effect of El Niño on EASP is different from that in the decaying stage.

\section{1) Direct impact of EI Niño on EASP}

We now perform a composite analysis of the EASP response in the developing stage based on the summer El Niño index defined in Section 2. This summer index is highly correlated with ( $\mathrm{r}=0.86$, Fig. 1$)$, but not identical to, the winter index that has been generally used in most previous studies (Huang and $\mathrm{Wu} 1998$; Wu et al. 2003; Yuan et al. 2012). This difference is caused by the complex temporal evolution pattern of El Niño, such that a strong El Niño in winter does not necessarily correspond to a strong El Niño SST anomaly in its developing summer. This can be seen in, for example, the later-developing El Niño in fall (e.g. 1968/1969, 1986/1987, 1994/1995). Compared with the traditional winter index (as indicated by the supplementary figure), our summer index gives a clearer and more robust signal for the summer.

The global SST composite anomalies in the developing summer of El Niño (Fig. 3a) show that the El Niño SST anomaly has been well established, with the maximum anomaly around $1.0^{\circ} \mathrm{C}$ in the eastern-central tropical Pacific. Furthermore, it is important to note that there is little SST anomaly in the rest of the global ocean. This occurs because the heat capacity of the surface ocean requires $\sim 2-3$ months for SST anomalies to be established by the surface heat flux. In the developing stage of El Niño, no significant equatorial Pacific SST anomaly is present in the preceding months and therefore there is no SST response outside the tropical Pacific caused by the teleconnection from ENSO SST anomaly yet. This is in contrast to the decaying summer, when significant SST anomalies in other oceans are forced by peak ENSO SST anomaly in the preceding winter (Kumar and Hoerling, 2003). In other words, in the developing summer, the newly established SST anomaly in the tropical Pacific has not sufficient time to generate significant SST anomalies in other oceanic basins. As a 
result, SST anomaly is significant only in the tropical Pacific. Therefore, if El Niño can influence EASP in the developing summer, the SST forcing should be dominated by that from the tropical Pacific.

Corresponding to the composite SST anomaly (Fig. 3a), there is a significant response in the precipitation over East Asia (Fig. 3b). The anomalously wet condition mainly occurs in northeastern and southern China, sandwiching a dry anomaly in northern China. The response amplitude for precipitation is around $10 \%$ (per $1{ }^{\circ} \mathrm{C}$ change of SST in the eastern-central tropical Pacific) in most areas of East China, which passes the $90 \%$ significant test except for southern China. This composite analysis is consistent with the GEFA response of the EASP to the leading EOF mode of the summer SST anomaly in the tropical Pacific (Wen et al. 2015). That consistency is due to the resemblance of the two SST forcing patterns (Fig. 3a here and Fig. 1a in Wen et al. 2015). The amplitude of the composite precipitation anomaly is about half of the GEFA response, is the signal being proportional to the strength of the composite SST anomaly in the eastern-central tropical Pacific. Our results are consistent with those of Huang and $\mathrm{Wu}$ (1989) and $\mathrm{Wu}$ et al. (2003, 2009). The consistency of results implies a good robustness of the relationship between the summer El Niño SST anomaly in the tropical Pacific and the EASP anomaly in the developing summer of El Niño. It should be noted that the composite precipitation response over southern China is less robust than those over central and northern China, as indicated by the lack of significant precipitation anomaly there in Fig. $3 b$. This is mainly due to a combined effect of different El Niño-SST forcing from different locations in summer. The response of southern China precipitation in summer to El Niño-SST forcing from the eastern tropical Pacific is almost opposite to that from the central tropical Pacific. A detailed study on this issue of different types of ENSO is out of the scope of the current paper, and will be presented in a separate paper. In summary, it is clear that El Niño exerts impact on summer precipitation in East Asia in its developing stage, and predominantly through direct influences of the El Niño SST anomaly from the tropical Pacific. There is weak interference from other oceanic 
basins.

\section{2) El Niño-induced circulation anomalies}

To understand the relation between El Niño and EASP in the developing summer, we examine the composite three-dimensional structure of atmospheric circulation anomalies over the globe.

First, in the tropics, the upper-level $200 \mathrm{hPa}$ geopotential height anomaly shows a pair of Rossby wave ridges straddling across the central equatorial Pacific with an amplitude of $\sim 10 \mathrm{~m}$ (Fig. 4a). Compared with the equatorial Rossby wave response to El Niño in winter, which is only confined in the central and eastern equatorial Pacific (e.g. Liu et al., 2012), the response in summer extends far westward with two 'wings' deep into the northwestern and southwestern subtropical Pacific. Relative to the southern ridge, the northern ridge of the Rossby wave extends far more poleward (northwestward) in the subtropical Pacific. This upper atmospheric response is accompanied by a lower-level $850 \mathrm{hPa}$ westerly anomaly in the equatorial Pacific and a strong ascending flow over the eastern-central Pacific in the middle troposphere (Fig. 4b). The tropical response is consistent with that to a deep equatorial heating (Gill, 1980).

Second, accompanying the anomalous high-pressure response over the entire tropics, there is a belt of low-pressure anomaly in the mid-latitude Northern Hemisphere (Fig. 4a), which reinforces the background circulation of the subtropical jet. Superimposed on the low-pressure belt, there is a circumglobal wave train with anomalous cyclone centers over the Mediterranean, the Iranian Plateau, Northeast Asia, the Central-North Pacific, off the California coast, the Great Lakes and the North Atlantic, as well as an anomalous anticyclone over Northwest Canada. The maximum response center is around 25 mover Northeast Asia, with the others of amplitudes around $10 \sim 15 \mathrm{~m}$. This wave train pattern is similar to the first dominant SVD mode of $200 \mathrm{hPa}$ geopotential height associated with tropical heating (Ding et al., 2011), except over Western Europe where the CGT exhibits an out-of-phase anomaly over European Russia, upstream of the Iranian Plateau (Ding et al., 2005). The 
difference occurs because the CGT mainly captures the geopotential height response to the heating of Indian summer monsoon, which is defined as the reference area to the Northwest of India $\left(60^{\circ} \mathrm{E} \sim 70^{\circ} \mathrm{E}, 35^{\circ} \mathrm{N} \sim 40^{\circ} \mathrm{N}\right)$, a point to be returned in section 4.

Third, the low level response exhibits an anticyclone over the northern Indian Ocean and a wave train that propagates northward along the coast of East Asia, with an anomalous cyclone over the western tropical Pacific, an anomalous anticyclone over the western North Pacific and an anomalous cyclone over East Asia-Northwest Pacific (denoted as ' $\mathrm{C}-\mathrm{A}-\mathrm{C}$ ' in Fig.4b). This wave train resembles closely to the 'brother' Pacific-Japan (PJ) pattern, which is found as the second EOF mode of the $850 \mathrm{hPa}$ vorticity in the area of $100^{\circ} \mathrm{E} \sim 160^{\circ} \mathrm{E}, 0{ }^{\circ} \mathrm{N} \sim 60^{\circ} \mathrm{N}$ in boreal summer (Kosaka and Nakanura, 2010a).

In summary, Fig. 4 reveals that there is a prominent atmospheric response over East Asia to the summer El Niño SST anomaly (in Fig.3a), which enables El Niño in its developing summer to impact the EASP.

We now focus on the sector of East Asia in Fig.5. It is clear that the composite precipitation anomaly in Fig.3b can be attributed to two circulation anomalies that are forced directly by El Niño: an anomalous low pressure in the upper atmosphere in Northeast Asia and an anomalous anticyclone in the western North Pacific in the lower atmosphere. At $500 \mathrm{hPa}$, a low pressure occurs in northeastern Asia, rendering the East Asian trough deepening and shifting southwestward into South China. Combined with the climatological air temperature gradient from Southwest to Northeast China (as indicated by the red contours in Fig.5a), this low pressure advects warm air in front of the trough from southern China into the East China Sea, and advects cold air behind the trough from Lake Baikal into southern China. As a result, air ascends in Southeast and Northeast China, and descends in North China. The $500 \mathrm{hPa}$ vertical velocity anomalies, shown in Fig.5b, roughly coincide with the wet and dry regions shown in Fig.3b. In addition, the low-level anomalous wind provides a favorable moisture condition for precipitation. 
As shown in Fig.5c, the anomalous anticyclone in the western North Pacific strengthens the western North Pacific subtropical high and makes it shift northeastward, which results in an enhanced moisture transport towards Southeast China. In Northeast China, the southerly wind anomalies over the southeastern tip of the anomalous cyclone in Northeast Asia vehicles abundant water vapor from its vicinity over the Japan Sea. The strong ascending and enhanced moisture supply from the South eventually intensify the rainfall in Southeast and Northeast China. To the contrary, the enhanced descending and the cold dry air from the North lead to dry conditions in northern China.

These composite results of atmospheric circulation response are consistent with those obtained with GEFA (see Fig.5 in Wen et al., 2015), in terms of both spatial pattern (spatial correlation $0.6 \sim 0.8$ ) and amplitude of response. The circulation responses that are part of the wave train along the East Asian coast are also consistent to that found in $\mathrm{Wu}$ et al. (2003). The anomalous cyclonic vorticity over WNP identified by $\mathrm{Wu}$ et al. (2003) is actually an expansion of the anomalous cyclone in the East of the Philippines in Fig.5c. These consistent results suggest there is a good robustness for the two key anomalous circulations impacting climate in East Asia, the anomalous low pressure in Northeast Asia and the anomalous anticyclone in the western North Pacific. They play a direct role in linking the EASP anomalies to those of El Niño SST anomalies in the developing summer of El Niño.

\section{Possible mechanisms}

The analysis above shows a clear anomalous circulation pattern that links the El Niño SST anomaly in the tropical Pacific with the East Asian climate in summer. It is mainly featured with a circumglobal wave train superimposed on a low-pressure belt in the midlatitude upper atmosphere, and a PJ-like wave train along the East Asian coast in the low level. The next question is how the El Niño SST anomaly in the tropical Pacific generates these circulation anomalies.

\section{1) Associated heating sources}

To investigate the mechanism, we first examine the precipitation anomaly 
stratified by the summer El Niño index to identify the forcings associated with latent heat release. Considering the small amplitude of precipitation anomalies in mid-high latitudes (not shown) and the large efficiency of tropical forcing on atmosphere, we mainly focus on anomalies of tropical precipitation and latent heat release. A common feature across all the four datasets is the presence of a tri-pole pattern, characterized by an anomalously abundant rainfall in the western equatorial Pacific elongated into the eastern equatorial Pacific and surrounded by deficient rainfalls over the maritime continent of Indonesia and over equatorial South America (Fig.6a-d). This tri-pole precipitation anomaly tends to shift the climatological precipitation toward the equatorial central Pacific, consistent with the observed precipitation change in the tropical Pacific in El Niño years (e.g. Wen et al., 2010). The precipitation anomalies also correspond well to the vertical velocity change in the middle troposphere, albeit with the disproportionately large amplitudes of vertical velocity over the eastern-central tropical Pacific relative to that over the western tropical Pacific (as shown in Fig.4b). The western tropical Pacific is located in the area of large climatological precipitation as shown in the black contour in Fig.6a. Thus, a small perturbation of the convection could lead to a substantial precipitation anomaly there. In contrast, the eastern-central Pacific lies in the relatively marine desert area with a low sea surface mean temperature, so that the ascending air has to reach a threshold to generate strong precipitation.

It should be noted that, in addition to the directly-induced precipitation anomaly, there is a robust negative precipitation anomaly over Northwest India, as shown in Fig.6. This negative precipitation anomaly is mainly related to the subsidence over the southwest maritime continent of Indonesia and its associated anticyclonic anomaly over the equatorial Indian Ocean. Such a situation can break the summer monsoon southwesterly wind and therefore reduce the Indian summer rainfall (as indicated in Fig.4b). This is consistent with previous studies on the failing Indian summer monsoon during the El Niño years (e.g. Kumar et al. 1997; Wang et al. 2003).

These heating sources and their associated vorticity perturbations may provide essential hints to understand how El Niño generates atmospheric circulation 
anomalies. As shown in Fig.4, this can be realized through: 1) the vertical motion-induced vorticity perturbation in the central and eastern equatorial Pacific,2) the dipole heating anomaly across the equatorial maritime continent of Indonesia, and 3) the suppressed heating over Northwest India that is indirectly induced by El Niño.

\section{2) Mechanism analysis}

To further explore the influence of the El Niño-induced heating sources on the atmospheric circulation anomaly in Fig.4, we calculate the vorticity, the wave activity flux and the velocity potential from the composite wind as shown in Fig.8 and 9. Based on these analyses and the summer climatological background circulation (Fig.7), we can deduce three pathways of atmospheric teleconnection in boreal summer that enables El Niño to impact the atmospheric circulation and, in turn, rainfall over East Asia.

\section{(1) Pathway 1: Circumglobal Pathway}

The circumglobal wave anomaly in mid-latitude (Fig.4a) is primarily generated by the vertical motion-related vorticity perturbation from the eastern-central tropical Pacific. In boreal summer, a distinct feature in the upper troposphere is the presence of the westerly subtropical jet around $40^{\circ} \mathrm{N}$, as indicated by the blue shading in Fig.7a. A wave train is outlined by the vorticity centers confined in the jet, most of which being statistically significant (as shown in Fig.8a). These zonally oriented vorticity anomalies are linked together by the distinct eastward wave activity flux in the belt of westerly jet.

The presence of the wave energy propagation along the westerly jet is not surprising since the jet acts as a waveguide (Branstator 2002). It is however unclear how the disturbances are excited by anomalies from the Pacific heating sources, given that the easterly mean flow in the tropics is unfavorable for the stationary Rossby wave to propagate into the extratropics. We believe that the key feature, is the secondary westerly jet and the corresponding westerly trough extending southwestward from $\sim(120 \mathrm{~W}, 40 \mathrm{~N})$ towards the tropics of $\sim(160 \mathrm{~W}, 20 \mathrm{~N})$, in the subtropical eastern-central North Pacific, deep into the central tropical Pacific Fig.7a). 
This westerly anomaly opens a 'window' of westerly duct in the eastern North Pacific double jet region, providing a potential way for the tropical Pacific ENSO signal to propagate into the mid-latitude and then to East Asia in the westerly wave guide (Webster and Holton, 1982).

As expected, Fig.8a shows a strong wave activity flux emanating from the negative vorticity center over the central subtropical Pacific, which corresponds to the El Niño-induced Rossby wave in the Northern Hemisphere (Fig.4a), to a positive vorticity off the California coast and then into the subtropical jet and wave guide over North America. This extratropical propagation occurs in the region of the mid-Pacific westerly trough, which provides several opportunities of the energy propagation from the tropics into the extratropics. First, the 'window' of westerly in the central tropical Pacific might play a role in communicating the Rossby waves from the tropics into the extratropics (Webster and Holton 1982). Second, the vorticity advection by the divergence flow in the central tropical Pacific (Fig.9a) could also help to transport perturbations into the westerly jet (Sardeshmukh and Hoskins 1988). Third, the southerly wind in front of the trough helps the vorticity anomaly in the central tropical Pacific to propagate into the subtropical jet (Wang et al., 2005).

\section{(2) Pathway 2: PJ-like wave train}

In contrast to the zonal wave train in the upper level, the low-level meridional wave propagation along the East Asian coast (Fig.4b) is mainly attributed to the dipole heating anomaly across the equatorial maritime continent of Indonesia. As shown in Fig.8b, a large positive vorticity anomaly over the western tropical Pacific emits energy flux into a negative vorticity center over the western North Pacific, and continues to propagate into the North Pacific. Corresponding to the northward wave activity flux in the low level, a southward flux in the upper level transmits from the positive vorticity over northern East Asia through the western North Pacific to the western-central tropical Pacific (Fig.8a).

These characters of the wave structure and energy propagation are similar to the 'brother' PJ pattern, which was found as the second EOF mode of the $850 \mathrm{hPa}$ 
vorticity over the East Asian region in boreal summer (Figure15 in Kosaka and Nakamura, 2010). Their analysis suggested a high efficiency of energy conversion for the meridional mode under the basic state of the subtropical jet over East Asia, the South and East Asian monsoon system, and the subtropical anticyclone in the western North Pacific (Fig.7a and b). In their case studies, Kosaka and Nakamura (2010) attributed this pattern to an anomalous convection near the Bonin Island.

In our case of summer El Niño, Fig. $8 \mathrm{~b}$ shows that the dominant diabatic heating that triggers this mode of meridional wave train is located in the western tropical Pacific, coincident with the large precipitation anomaly over there (Fig.6). The anomalous cyclone/anticyclone over the western tropical Pacific in the low/upper level is therefore likely caused by the Rossby wave response to the summer El Niño SST anomaly in the eastern-central tropical Pacific. The baroclinic atmospheric response reinforces the convection, resulting in an abundant rainfall over the western tropical Pacific (Fig.6). The northwestward extension of the precipitation anomaly perturbs the western Pacific monsoon trough, and further excites the northward propagation of Rossby wave along the East Asia coast. The slight deficiency of the rainfall over Bonin Island (Fig.6) is probably a product of the dynamic process associated with the meridional mode. Besides the western tropical Pacific heating, there might also be a contribution from the large negative precipitation anomaly over the southwest maritime continent of Indonesia, where the subsidence is tightly connected with the air ascending across the equator over the maritime continent as indicated by the divergence and convergence marked in Fig.9b. Furthermore, the meridional pattern shown in Fig.4b might also involve an influence from the zonal wave propagation in mid-latitude, especially for the northern portion of the wave train over the North Pacific, which indicates the complicity of the meridional mode presented here, a point to be returned later.

\section{(3) Pathway3: South Asia Path}

In addition to the two direct effects of El Niño on the circulation anomaly discussed above, we can also see an indirect effect originating from the diabatic 
542 heating over Northwest India. The robust negative precipitation anomaly over

543 Northwest India (Fig.6) is caused by an anomalous anticyclone over the tropical

544 Indian Ocean that breaks the Indian monsoon westerly (Fig.4b). The anticyclone is

545 mainly induced by the subsidence over the southwest maritime continent of Indonesia.

546 As demonstrated by Wang et al. (2003), the sinking branch of the anomalous Walker

547 circulation induced heating centered on the equatorial Maritime Continent, which

548 could generate an asymmetric Rossby wave response biased to the Northern

549 Hemisphere, in the presence of the mean easterly vertical shear, as indicated in Fig.7a

550 and $\mathrm{b}$, a pronounced southwesterly monsoon over the North Indian Ocean

551 corresponding to a strong upper-level easterly wind on the south edge of the South

552 Asian High. In addition to the dominant influence of the subsidence over the Maritime

553 Continent to the northwest of Australia, there may also be a contribution from its

554 neighbor air ascending over the western tropical Pacific. As shown in Fig.9a and b,

555 the suppressed heating over Northwest India induces a large convergence and

556 divergence flow in the upper and low level, forming the second center of the velocity

557 potential over there. The convergence flow in the upper level is so close to the

558 subtropical jet such that it could be another potential perturbation source of the

559 zonally propagating wave train in the westerly wave guide (Fig.8a).

560

561

562

563

564

\section{El Niño Direct and Indirect Heating Effects}

We now further separate the atmospheric responses to the direct and indirect heatings of the summer El Niño using the partial regression method. Here, the direct heating refers to those over the eastern-central tropical Pacific and the western Pacific (due to the strong co-variability of the two heating anomalies, it is difficult to do further separation of their impacts in observation), while the indirect heating refers to that over Northwest India (Fig.6).

The direct El Niño heating is represented by the so called Pacific heating index (PHI) that is defined as the normalized principle component of the first leading EOF mode of the PREC precipitation over the tropical Indo-Pacific region $\left(70^{\circ} \mathrm{E} \sim 80\right.$ ${ }^{o} \mathrm{~W}, 20{ }^{\circ} \mathrm{S} \sim 10^{\circ} \mathrm{N}$ ) (the red curve in Fig.10c). As shown in Fig.10a, a dipole 
571 precipitation anomaly straddles across the equatorial Maritime Continent with the positive node tilting into the northern western-central tropical Pacific. This pattern is similar to the composite precipitation anomaly in both the spatial pattern and amplitude (Fig.6a).

For the indirect Indian heating index (IHI) over Northwest India, we use the domain averaged precipitation anomaly over Northwest India $\left(60^{\circ} \mathrm{E} \sim 88^{\circ} \mathrm{E}, 15^{\circ} \mathrm{N}\right.$ $\sim 35^{\circ} \mathrm{N}$ ) (the blue curve in Fig.10c). As shown in Fig.10b, besides the primary negative precipitation anomaly over Northwest India with amplitude about one-third larger than that in Fig.6, the regression map on IHI also shows a moderate heating over the western and eastern tropical North Pacific. This indirect heating index IHI has relatively low, albeit statistically significant, correlation with the direct heating index of $\sim 0.3$ (on PHI), indicating the substantial independence of the India summer monsoon heating. We note that our major conclusion below is insensitive to the choice of the size or shift of these domains for the definition of these indices of the El Niño-induced heating sources.

\section{1) Direct heating effect}

The atmospheric response to the direct heating is widespread (Fig. 11a, b). In the upper level, it shows a cross-equator Rossby wave response in the eastern-central tropical Pacific with a maxinum amplitude around 10-m, and a wave train response superimposed on a low-pressure belt in the mid-latitudes. The response pattern is quite similar to the atmosphere anomaly in Fig.4a, indicating a major role of the direct heating there. The zonal contrast of the atmospheric response with the anomalous high (low) in the tropics (extratropics) is also consistent with the finding of Ding et al. (2011). Furthermore, in mid-latitude, the atmospheric response bears some resemblance to the PNA response over the Northeast Pacific and America sector, with an anomalous low pressure off the California coast, an anomalous high over Northwest Canada, and an anomalous low over Northeast America. Besides these anomaly centers; there are also low-pressure centers with amplitude $\sim 10 \mathrm{~m}$ over the North Atlantic, the Mediterranean and Caspian Sea, Northeast Asia and the Northwest 
Pacific, forming a zonal wavenumber 5 wave train in the westerly jet. This is in line with the theoretical study on the preferential wavenumber of the zonally stationary Rossby wave in the waveguide of summer subtropical jet (Hoskins and Ambrizzi 1993; Branstator 2002). In the lower level, besides the westerly anomaly in the equator Pacific in local response to the El Niño warming, the atmospheric response to the direct heating shows an anomalous anticyclone over the tropical India Ocean and a meridional wave train along the East Asian coast (as indicated by the markers in Fig. 11b), which resembles the total low-level response in Fig.4b. This indicates the major contribution of the direct heating to the low level, consistent with the above discussion of the dynamic response of the South and East Asian circulation to the dipole heating across the equator Maritime Continent.

\section{2) Indirect heating effect}

In spite of the dominant global response to the direct heating, there is also a significant contribution from the indirect heating from Northwest India to the East Asia region (Fig. 11c, d). The local atmospheric response to the Indian summer rainfall anomaly is an anticyclone anomaly in the low level and a large cyclone anomaly over the northwest of the heating in the upper level with amplitude around $10 \mathrm{~m}$, consistent with a Rossby wave response to an anomalous heating over the Indian region (Rodwell and Hoskins 1996). In mid-latitude, the upper atmospheric response also exhibits a circumglobal wave train along $\sim 40^{\circ} \mathrm{N}$ with a wave number 5 structure. The distinct feature of this wave train is that the most anomaly centers (with amplitude around $10 \sim 15 \mathrm{~m}$ ) are mainly confined within the Eurasia-North Pacific sector, with an anticyclone over European Russia, a broad cyclone over the Iranian Plateau, a smaller anticyclone over the southwest of Lake Baikal, and two linked cyclones over Northeast Asia and the central-North Pacific. The wave train pattern is identical to the MAS pattern ( $\mathrm{Wu}, 2002)$, and bears some resemblance to the CGT pattern defined by Ding and Wang (2005). Although this wave train does not coincide with that generated by the direct heating (Fig.11c vs Fig.11a), over East Asia, both show a cyclone response, with the response to the indirect heating somewhat 
southward, covering a large portion of eastern China. Therefore, although the indirect heating is much less important for the global response, it seems to have an impact on East Asia comparable to that of the direct heating.

\section{3) Combined response to El Niño-induced heatings}

Finally, we show that the total atmospheric response in Fig. 4 could be reproduced using the partial regression of the atmospheric response to the direct heating in the tropical Pacific combined with that to the indirect heating over Northwest India. Compared with the composite precipitation anomaly in Fig.6a, the regressed precipitation anomalies on these El Niño-induced heating indices show a comparable amplitude over the tropical Indo-Pacific in Fig. 10a (on PHI), and a one-third larger deficient rainfall over Northwest India in Fig. 10b (on IHI). Therefore, the combined atmospheric response is constructed with the partial regressions weighted by 1.0 and 0.7 for the El Niño-induced precipitation anomaly in the tropical Indo-Pacific (Fig. 11a and b) and the suppressed heating over Northwest India (Fig. $11 \mathrm{c}$ and d), respectively. The result in Fig. 12 is comparable to the composite response in Fig. 4 both in the spatial pattern (the cross-equator Rossby wave response in tropical Pacific, the zonal wave train superimposed on the low-pressure belt in mid-latitude, and the meridional propagating wave along the East Asian coast) and the response amplitude. The pattern correlation of the combined $200 \mathrm{hPa}$ geopotential height (Fig. 12a) with the composite response in Fig. $4 \mathrm{a}$ is around 0.89, and the amplitude ratio of the absolute value over the observed one is about 0.80 . The slight smaller atmospheric response both in the tropical Pacific and mid-latitude is probably attributable to the underestimation of the vertical perturbation over the eastern-central tropical Pacific, as indicated by the vertical velocity in Fig. 12b. That's because the PHI index-associated vertical motion mainly captures the El Niño precipitation-related moisture process, but underestimates the El Niño SST anomaly-induced dry dynamic process. In the low level, compared with the meridional wave in Fig. 11b, the combined response (Fig. 12b) is more consistent with observation in Fig. 4b. This indicates the role of the atmospheric response to the 
658 India summer rainfall in maintaining and reshaping the pattern, especially for its

659

660

661

662

663

664

665

666

667

668

669

670

671

672

673

674

675

676

677

678

679

680

681

682

683

684

685

686

northern portion of the wave train. The resemblance of the combined response to the total response demonstrates the dominant contribution of the El Niño-induced direct heating over the tropical Pacific to the global scale circulation anomaly, and the comparable effect of the indirect (negative) heating over Northwest India on the atmospheric anomaly over East Asia in the developing summer of El Niño.

\section{Conclusion and Discussions}

This paper is a further attempt to understand the impact of El Niño in its developing summer on the East Asian summer precipitation (EASP). Although El Nino is not yet at its fully-developed stage, our composite analysis shows that there is a significant direct impact of El Niño on EASP, with the SST anomaly in the eastern-central tropical Pacific as the dominant forcing. The corresponding precipitation anomaly is characterized by a pair of abnormal rainfall in northeastern and southeastern China, sandwiching a deficient rainfall in northern/central China. This tri-pole precipitation anomaly of EASP can be attributed to two key circulation anomalies induced by El Niño: an anomalous cyclone in the upper atmosphere in Northeast Asia and an anomalous anticyclone in the lower atmosphere in the western North Pacific. The anomalous cyclone provides a favorable condition for ascending over Southeast and Northeast China, and for descending over northern China, while the anomalous anticyclone provides the moisture supply into Southeast China.

These circulation anomalies are forced by El Niño in three teleconnection pathways, as indicated schematically in Fig. 13. First, the direct heating associated with the eastern-central Pacific SST anomaly induces the vertical motion and then the upper level vorticity perturbation over the eastern-central tropical Pacific; this upper level vorticity perturbation is located in the vicinity of the subtropical trough in the central tropical Pacific, enabling a stationary Rossby wave propagating into the waveguide of the subtropical jet and then to East Asia in the circumglobal teleconnection wave train (Branstator 2002; Ding and Wang 2005). Second, the direct heating of dipole structure across the equatorial Maritime Continent that is associated 
with the high precipitation over the western tropical Pacific and the large subsidence over Northwest Australia could generate a northward propagation of Rossby wave along the east coast of East Asia under the background state of the East Asian climate (Kosaka and Nakanura 2010). Third, the indirect heating generated by El Niño with suppressed rainfall over Northwest India could also excite a perturbation in the subtropical jet due to its proximity to the jet, and in turn affect the East Asia through the wave guide ( $\mathrm{Wu} 2002)$.

These mechanisms are also confirmed by a partial regression analysis of the atmospheric response to direct heating and indirect heating induced by El Niño In response to the El Niño-induced direct heating, a broad wave train response is generated that overlaps $s$ with a low pressure anomaly belt in the mid-latitude in the upper level; in addition, a meridional wave train is also generated along the East Asia coast in the low level. Both have major contributions to the summer El Niño-induced circulation anomaly. In response to the El Niño-induced indirect heating over Northwest India, the zonal wave train response in the upper mid-latitude is mainly confined in the Eurasian sector, which contributes to about one-third to the El Niño-induced circulation anomaly over these regions. Furthermore, the summer El Niño-induced circulation anomaly could be well reproduced by the linear combination of the atmospheric responses to the direct and indirect heatings.

A particularity of our study is the use of summer El Nino SST index to investigate impacts of developing El Nino on summer rainfall in East Asia, while most previous studies (Lin and Yu 1993; Gao and Wang 2007; Zong et al. 2010) used the winter El Niño SST signal for the prediction of EASP in the following summer. As shown in Fig.1, it is clear that EASP responses are both important, but different for the developing and decaying summers of El Niño. The EASP in the developing summer shows a robust interannual variability correlated with El Niño. For instance, in the summers of 1965, 1969, 1972, 1982, 1991, 1997 and 2002 (the developing stage of El Niño), northern China experienced droughts of various degrees, accompanied by unusually high precipitation in the Jianghuai River Basin and southeast China. However, in the developing summers of La Niña (1964, 1970, 1973, 
$1988,1995)$, the precipitation anomalies are roughly opposite over these regions. Our study here presents a more comprehensive analysis of the relation between the EASP and El Niño during its developing stage. Furthermore, we deduced a few mechanisms through which summer El Niño impacts the atmosphere.

Our findings should help to clarify some controversies in previous results (Huang and Wu 1989; Zhang et al. 1996; Wu et al. 2003; Wu et al. 2009; Zhu and Li 2016). Our study provides a clearer picture on how the El Niño-induced atmospheric circulation anomaly forces the EASP anomaly in the developing summer. The understanding of the summer El Niño impact on the EASP implies some predictability of the EASP in the El Niño developing stage from the SST prediction from coupled climate models (http://iri.columbia.edu/our-expertise/climate/forecasts/enso/current/) and the observation-diagnosed response of the EASP anomaly to summer El Niño in this study.

It should be noted that our study here mainly distinguishes the ocean impact on the EASP in the developing stage of El Niño. There might be other factors such as heating over the Qinghai-Tibet Plateau, snow cover in Eurasia and land vegetation process and so on (Wu 2004; Wu et al. 2009; Chen et al. 2016). Comprehensive investigation and coupled model simulations on this topic will be addressed in future work. In addition, under the global warming, whether the relation of the EASP with summer El Niño will be changed is also an interesting topic to study.

\section{Acknowledgement}

Authors thank Prof. Tim Li for constructive discussions. This work is supported by Chinese NSFC41475089, NSFC41005048, US NSF AGS-1656907 and Chinese MOST 2017YFA0603801.

\section{References}

1. Adler, R.F., G. J. Huffman, A. Chang, et al., 2003: The Version 2 Global Precipitation Climatology Project (GPCP) Monthly Precipitation Analysis (1979-Present). J. Hydrometeor., 4, 1147-1167.

2. Branstator, G., 2002, Circumglobal Teleconnection, the Jet Stream Waveguide, and the North Atlantic 0scillation, J. Climate, 15, 1893-1910 
3. Chen H., Y. Zhang, M. Yu, W. Hua, S. Sun, X. Li, C. Gao. 2016, Large-scale urbanization effects on eastern Asian summer monsoon circulation and climate. Clim. Dyn., 47(1):117-136. doi:10. 1007/s00382-015-2827-3.

4. Chen, M., P. Xie, J. E. Janowiak, et al., 2004:Verifyingthe reanalysis and climate models outputs using a 56-year data set of reconstructed global precipitation. Preprints, $14^{\text {th }}$ Conf. on Applied Climatology, Seattle, WA, Amer. Meteor. Soc., J6. 1.

5. Ding, Q., B. Wang, J. M. Wallace, and G. Branstator, 2011: Tropical-extratropical teleconnections in boreal summer: Observed interannual variability. J. Climate, 24, $1878-1896$.

6. Ding, Q., B. Wang, 2005, Circumglobal Teleconnection in the Northern Hemisphere Summer, J. Climate, 18 (17) :3483-3505

7. Enomoto, T., B. J. Hoskins, and Y. Matsuda, 2003, The formation mechanism of the Bonin High in August, Quart. J. Roy. Meteor. Soc., 129, 157-178

8. Fu, Congbin, 1987: A review of study on E1 Niño/Southern 0scillation associated with the interannual climate variability. Scientia Atmospherica Sinica, 11(2), 209-220 (in Chinese)

9. Gao, H., and Y. Wang, 2007: On the Weakening Relationship between Summer Precipitation in China and ENSO. Acta Meteorologica Sinica, 65(1), 131-137.

10. Gi1l, A. E., 1980: Some simple solutions for heat-induced tropical circulation. Quart. J. Roy. Meteor. Soc., 106, 447-462.

11. Hoskins, B. J. and T. Ambrizzi, 1993, Rossby wave propagation on a realistic longitudinally varying flow, J. Atmos. Sci., 50, 1661-1671

12. Hoskins, B. J., and D. J. Karoly, 1981: The steady linear response of a spherical atmosphere to thermal and orographic forcing. J. Atmos. Sci., 38, 1179-1196.

13. Huang, Ronghui, and Y. Wu, 1989: The influence of ENSO on the summer climate change in China and its Mechanism. Advances in atmospheric Sciences, 6(1), $21-32$.

14. Hu, Z. Z., R. Wu, J. L. Kinter Ш, and S. Yang, 2005, Connection of summer rainfal1 variations in South and East Asia: Role of E1 Niño-southern oscillation, 
International Journal of Climatology, 25, 1279-1289

778

15. Kalney, E., and coauthor, 1996: The NCEP/NCAR 40-year reanalysis project. Bu11. Amer. Metero. Soc., 77, 437-471.

16. Kosaka, Y., H. Nakamura, 2010b: Mechanisms of meridional teleconnection observed between a summer monsoon system and a subtropical anticyclone. Part II: A global survey, J. Climate, 23, 5109-5125.

17. Kosaka, Y., H. Nakamura, 2010a: Mechanisms of meridional teleconnection observed between a summer monsoon system and a subtropical anticyclone. Part I: The Pacific-Japan pattern, J. Climate, 23, 5085-5108.

18. Kripalani, R. and A. Kulkarni, 2001, Monsoom rainfall variation and teleconnections over South and East Asia, International Journal of Climatology, $21, \quad 603-616$

19. Kripalani, R. and A. Kulkarni, 1997, Climatic impact of E1 Niño/La Niña on the Indian monsoon: A new perspective. Weather, 52(2), 39-46

20. Krishman, R. and M. Sugi, 2001, Baiu rainfall variability and associated monsoon teleconnections, J. Meteor. Soc. Japan, 79, 851-860

21. Kumar A. and M. Hoerling, 2003: The nature and causes for the delayed atmospheric response to E1 Niño. 16, J. Clim., 1391-1403

22. Kumar, K. K., M. K. Soman and K. R. Kumar, 1997, Seasonal forecasting of Indian summer monsoon rainfa11: A review, Weather, 50, 449-467

23. Li, Z.X., and S. Coni1, 2003: Transient Response of an Atmospheric GCM to North Atlantic SST Anomalies. J. Climate, 16, 3993-3998.

24. Lin, X., S. Yu, 1993: E1 Niño and Rainfall During the Flood Season (June-August) in China. Acta Meteorological Sinica, 51(4), 434-441 (in Chinese)

25. Liu, Y., Y. Ding, 1992: Influence of ENS0 events on weather and climate of China. Quarterly journal of applied meteorology, 3(4), 473-481.

26. Liu Z, Wen N, Fan L. 2012: Assessing Atmospheric Response to Surface Forcing in the Observations. Part I: Cross Validation of Annual Response using GEFA, LIM and FDT. Journal of Climate, 25(19):6817-6834. 
27. Liu, Z., and M. Alexander, 2007: Atmospheric bridge, oceanic tunnel, and global climatic teleconnections. Rev. Geophys., 45:RG2005. doi:10. 1029/2005RG000172

28. Mitche11, T. D. and P. D. Jones, 2005: An improved method of constructing a database of monthly climate observations and associated high-resolution grids, Int. J. Climatol., 25, 693-712

29. Nitta, Ts., 1987: Convective activities in the Tropical Western Pacific and their impact on the Northern Hemisphere summer circulation. J. Metero. Soc. Japan, 65(3), 373-390.

30. Peng, S., and J.S. Whitaker, 1999: Mechanisms determining the atmospheric response to midlatitude SST anomalies. J. Clim., 12, 1393-1408.

Rodwe11, M. J. and B. J. Hoskins, 1996, Monsoons and the dynamic of deserts, Quart. J. Roy. Meteor. Soc., 122, 1385-1404

31. Sardeshmukh, P. and B. J. Hoskins, 1988, The generation of global rotational flow by steady idealized tropical divergence, J. Atmos. Sci., 45, 1228-1251

32. Takaya, K. and H. Nakamura, 2001: A formulation of a phase-independent wave-activity flux for stationary and migratory quasi-geostrophic eddies on a zonally varying basic flow, J. Atmos. Sci., 58, 608-627

33. Wang, Z., C. -P. Chang, B. Wang and F. F. Jin, 2005, Teleconnections from tropics to Northern extratropics through a southerly conveyor, J. Climate, 62, 4057-4070

34. Wang, B., R. Wu, and T. Li, 2003: Atmosphere - warm ocean interaction and its impact on Asian-Australian Monsoon variability. J. Climate, 16, $1195-1211$.

35. Wang, B., and Q. Zhang, 2002: Pacific-East Asian Teleconnection. Part II : How the Philippine Sea Anomalous Anticyclone is Established during El Niño Development. J. Climate, 15, 3252-3265.

36. Webster, P. J and J. R. Holton, 1982, Cross-equatorial response to middle-latitude forcing in a zonally varying basic state, J. Atmos. Sci., 39, $722-733$

37. Wen N, Frankignoul C, Gastineau G., 2016 Active AMOC-NAO coupling in the IPSL-CM5A-MR climate mode1. Climate Dynamics, 47(7-8):2105-2119. 
38. Wen, N., Z. Liu, Y. Liu, 2015: Direct impact of E1 Niño on East Asian summer precipitation in the observation. Clim. Dyn., 44, 2979-2987.

39. Wen, N., Liu Z Y, Liu Q Y, et al. 2010, Observed atmospheric responses to global SST variability modes: a unified assessment using GEFA. Journal of Climate, $23(7): 1739-1759$.

40. Wu, B., T. J. Zhou and T. Li, 2009, Seasonally Evolving Domiant Interannual Variability modes of East Asian Climate, J. Climate, 22, 2992-3005

41. Wu B, Yang K, Zhang R. 2009. Eurasian snow cover variability and its association with summer rainfall in China. Adv Atmos Sci, 26: 31-44

42. Wu, Guoxiong. 2004: Recent Progress in the Study of the Qinghai-Xizhang Plateau Climate Dynamics in China, Quarternary Sci., 24(1): 1-9

43. Wu, Renguang, 2017, Relationship between Indian and East Asian summer rainfall variations, Adv. Atmos. Sci., 34(1):4-15

44. Wu, R. G., Z. Z. Hu, B. P. Kirtman, 2003: Evolution of ENS0-Related Rainfall Anomalies in East Asia. J. Clim., 16, 3742-3758.

45. Wu, R., 2002: A mid-latitude Asian circulation pattern in boreal summer and its connection with the Indian and East Asian summer monsoons. Int. J. Climatol., 22, $1879-1895$.

46. Wu, Z. W., JP. Li, ZH. Jiang, et al, 2012: Possible effects of the North Atlantic Oscillation on the strengthening relationship between the East Asian Summer monsoon and ENSO. Int. J. Climatol., 32, 794-800.

47. Xie, Shang-Ping, Kaiming Hu, Hafner Jan, et al., 2009: Indian Ocean capacitor effect on Indo-western Pacific climate during the summer following E1 Niño. J. Climate, 22, $730-747$.

48. Yang, J., Q. Liu, S-P. Xie, et a1., 2007: Impact of the Indian 0cean SST basin mode on the Asian summer monsoon. Geophys. Res. Lett., 34, L02708, doi:10. 1029/ 2006GL028571.

49. Yuan. Y., and S. Yang, 2012: Impacts of Different Types of E1 Niño on the East Asian Climate: Focus on ENSO Cycles. J. Climate, 25(21), 7702-7722. 
864 50. Zhang, R., A. Sumi, M. Kimoto, 1996: Impact of E1 Niño on the East Asian monsoon:

865

866

867

868

869

870

871

872

873

874

875

876

877

878
A diagnostic study of the 86/87 and 91/92 events. J. Meteor. Soc. Japan, 74, $49-62$.

51. Zhang, R. H. , A. Sumi, M. Kimoto, 1999: A diagnostic study of the impact of E1 Niño on the precipitation in China, Adv. Atmos. Sci., 16, 229-241

52. Zhang, R. H. , 2001: Relations of Water Vapor Transport from Indian Monsoon with That over East Asia and the Summer Rainfall in China, Adv. Atmos. Sci., 18, $1005-1017$

53. Zhu, Z., T. Li, 2016: A new paradigm for continental U.S. summer rainfall variability: Asia-North America teleconnection. J. Climate, 29(20), $7313-7327$.

54. Zong, H., L. Chen, and Q. Zhang, 2010: The Instability of the Interannual Relation between ENSO and the Summer Rainfall in China. Chinese Journal of Atmospheric Sciences, 34(1), 184-192. 
879

880

881

882

883

884

885

886

887

888

889

890

El Nino index compare in winter and summer

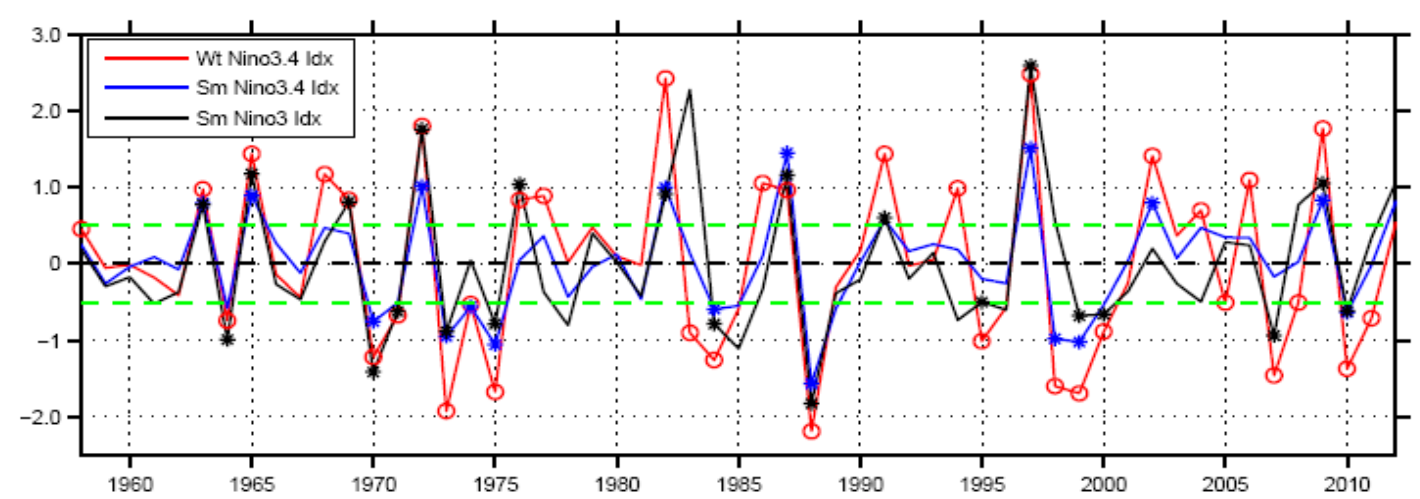

Figure 1 Comparison between the winter and summer El Niño indices. The red curve shows the Nino3.4 index in winter with red circles indicating El Niño/La Niña events. The blue and black curves show the developing summer Nino3.4 and Nino3 SST anomalies respectively with symbol 'star' marking values greater/less than $+/-0.5^{\circ} \mathrm{C}$ (as indicated by the green dash lines). As indicated, the strong El Niño cases are in the years of 1963/1964, 1965/1966, 1969/1970, 1972/1973, 1976/1977, 1982/1983, 1987/1988, 1991/1992, 1997/1998, 2002/2003 and 2009/2010, and the strong La Niña cases are in the years of 1964/1965, 1970/1971, 1971/1972, 1973/1974, 1974/1975, 1975/1976, 1984/1985, 1988/1989, 1995/1996, 1999/2000, 2000/2001, 2007/2008 and 2010/2011, respectively. 
Prec. Anomaly with El Nino Evolution

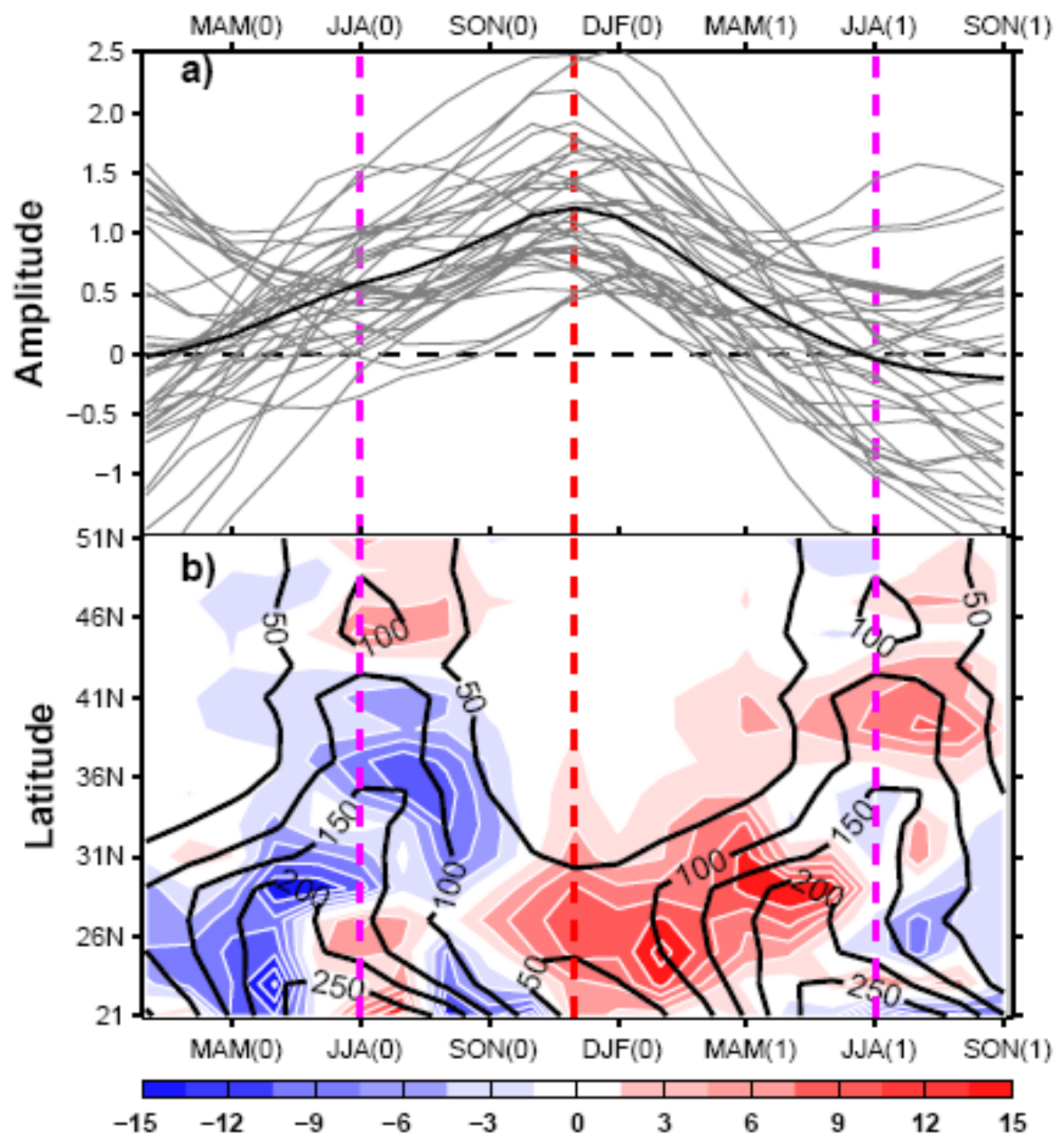

Figure 2 Temporal evolution of El Niño and the corresponding zonal mean precipitation anomaly in East Asia. a) Three monthly mean SST anomalies (unit: ${ }^{\circ} \mathrm{C}$ ) in Nino-3.4 region from February, March and April (FMA) of the developing year to September, October and November (SON) of the following year. The gray solid lines are for each individual El Niño event from 1958 to 2012. b) Zonal mean precipitations anomalies (unit: mm) in East Asia (East of 110E) corresponding to the ensemble mean of all El Niño events (thick black line in Fig.a). The shading indicates anomalies, and the black contours (contour interval of 50 $\mathrm{mm} / \mathrm{month})$ denote the seasonal cycle of mean climatology. The developing summer (JJA(0)), mature winter $(\mathrm{NDJ}(0))$ and decaying summer $(\mathrm{JJA}(1))$ of El Niño are highlighted by the three colored dash lines from left to right respectively. The numerals " 0 " and " 1 " in $\mathrm{X}$-coordinate indicate the El Niño developing and decaying years respectively. 
a) SST Comp. based on Sm EINino Index $(\mathrm{Sm} 0)$

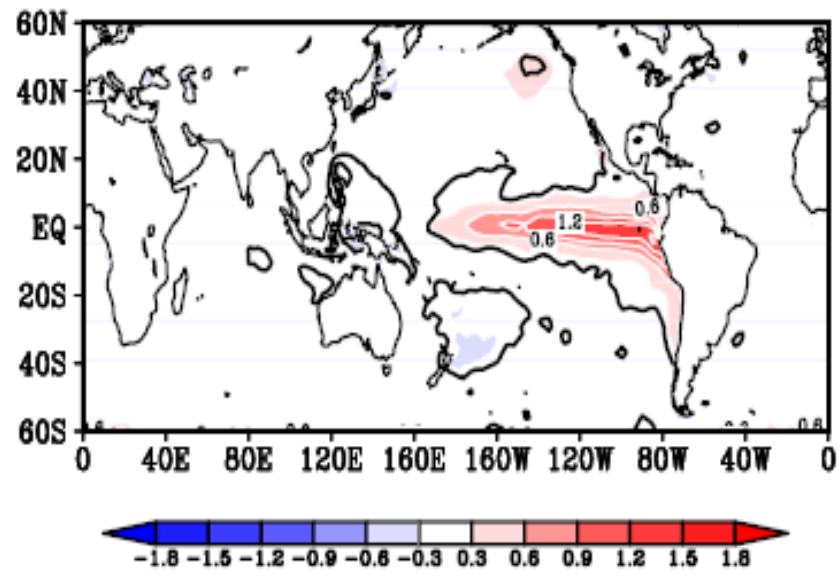

b) Prec. Comp based on Sm ElNino Index $(\operatorname{Sm0})$

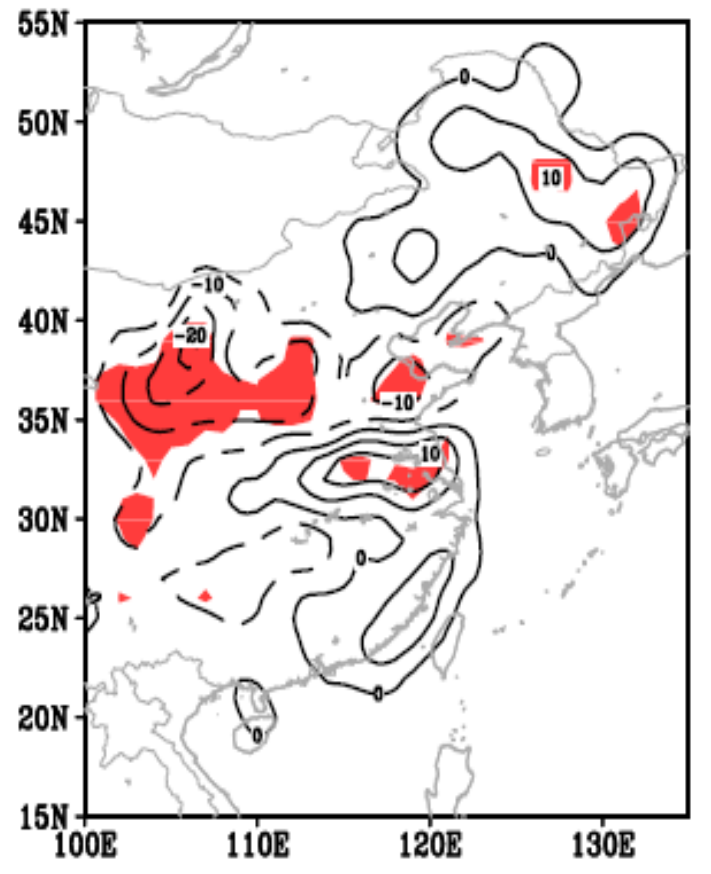

Figure 3 a) Composite global SST anomalies based on summer El Niño index. The red (blue) shading with white solid (dashed) line is for the positive (negative) value with contour interval (CI) of $0.3{ }^{\circ} \mathrm{C}$. b) Corresponding composite summer precipitation anomalies (relative variation, in percentage) over East Asia. The solid (dashed) line denotes the positive (negative) values with $\mathrm{CI}=$ 5\%. The thick black contour in Fig. a and red shaded in Fig. b indicates the 90\% confidence level. 
a) Z200 Comp on Sm El Nino Index $(\mathrm{Sm0})$

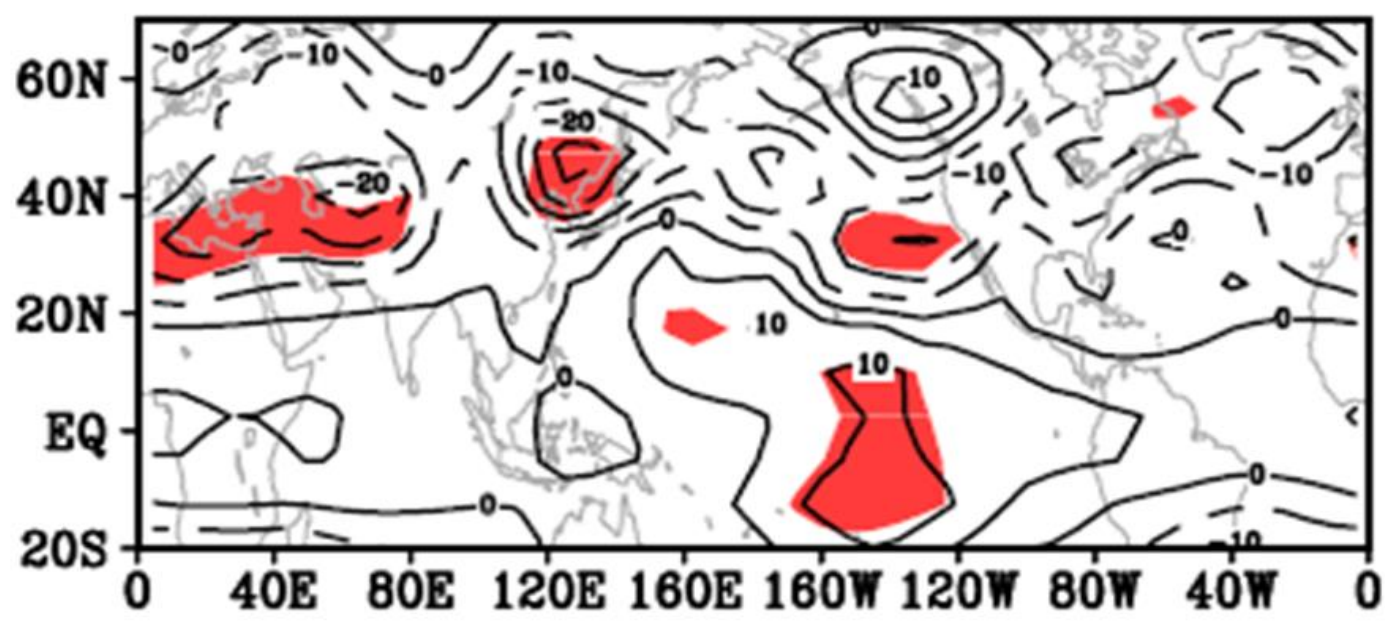

b) uv850/- $\omega 500$ Comp on Sm El Nino Index(Sm0)

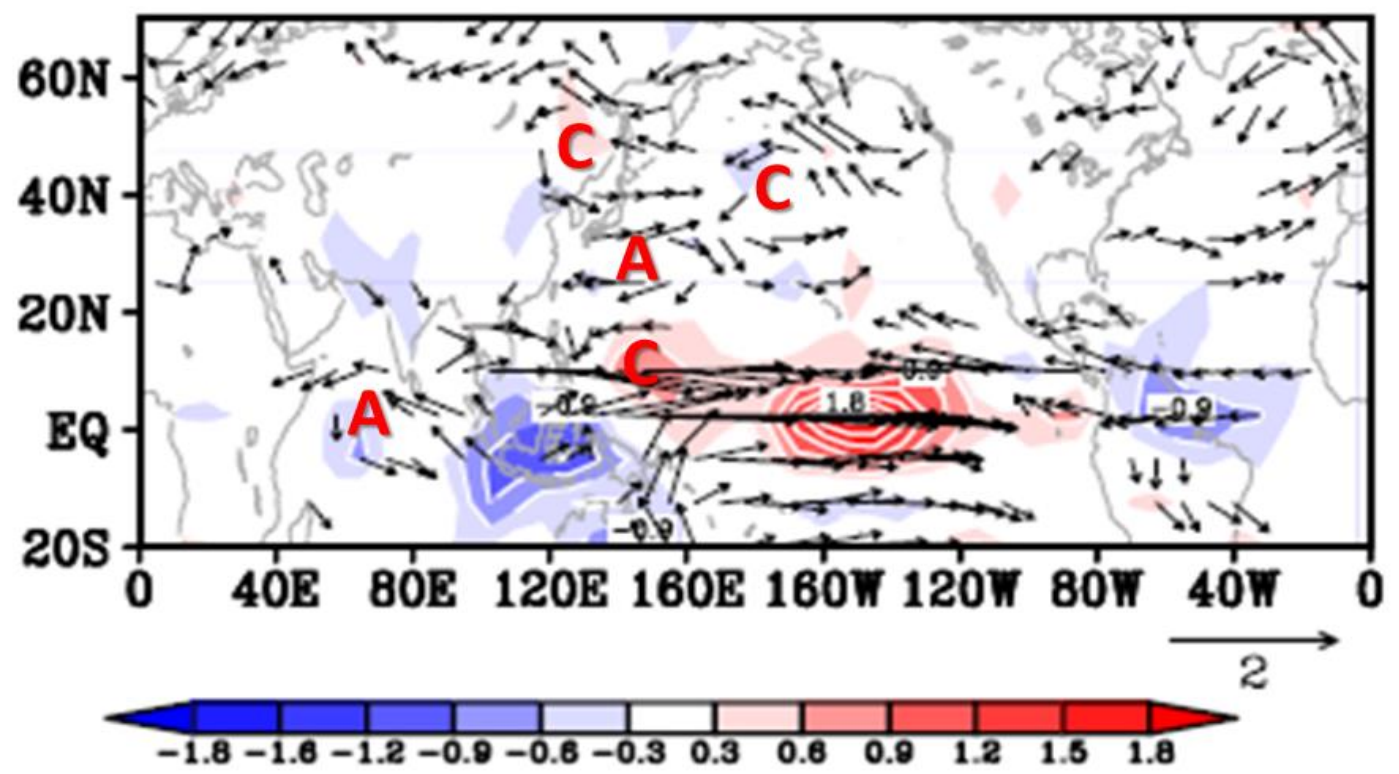

Figure 4 Composite atmospheric anomalies in the tropical-northern hemisphere of a) $200 \mathrm{hPa}$ geopotential height. Solid (dashed) line for positive (negative) value with contour interval (CI) of $5 \mathrm{~m}$. The shaded indicates the $90 \%$ confidence level. b) $850 \mathrm{hPa}$ wind (vector, unit: $\mathrm{m} / \mathrm{s}$ ) as well as $500 \mathrm{hPa}$ vertical velocity (omega with opposite sign $(-\omega)$, shaded). The small value of the wind (magnitude less than $0.3 \mathrm{~m} / \mathrm{s}$ ) is omitted in the figure. Red letters " $\mathrm{C}$ " and " $\mathrm{A}$ " mark cyclone and anticyclone respectively. And, the red (blue) shading with white solid (dash) line $\left(\mathrm{CI}=0.3 \times 10^{-2} \mathrm{~Pa} / \mathrm{s}\right)$ indicates the air ascending (descending). 

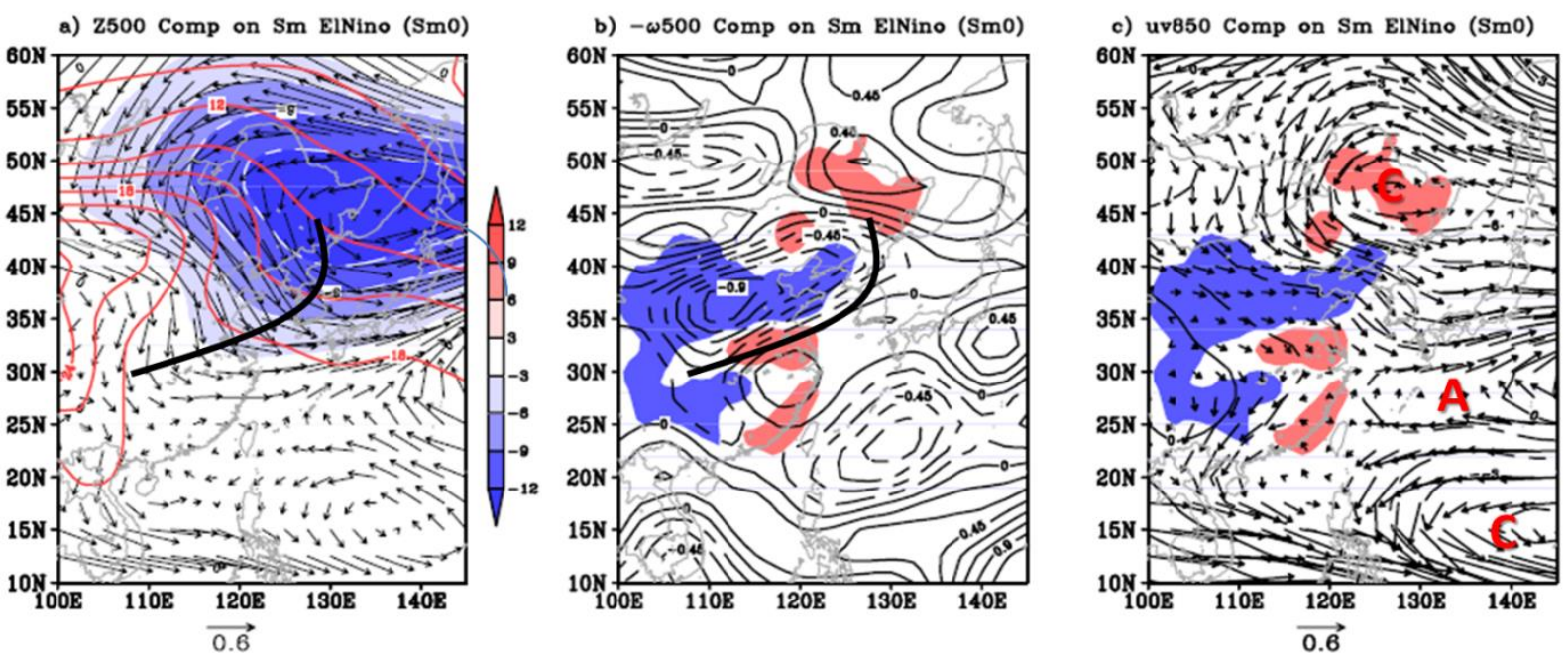

Figure 5 Atmosphere anomalies composites over East Asia in the developing summer of El Niño for a) $500 \mathrm{hPa}$ geopotential height (shaded, the blue (red) shading with white dash(solid) line for negative(positive) value, $\mathrm{CI}=3 \mathrm{~m}$ ) and $500 \mathrm{hPa}$ wind (vector, unit: $\mathrm{m} / \mathrm{s}$ ) with superimposed climatological mean air temperature at $850 \mathrm{hPa}$ (red contours, $\mathrm{CI}=2{ }^{\circ} \mathrm{C}$ ); b) $500 \mathrm{hPa}$ vertical velocity $(-\omega)$ (contours, solid (dash) line for the positive (negative) value with CI of $0.15 \times 10^{-2} \mathrm{~Pa} / \mathrm{s}$ ); c) $850 \mathrm{hPa}$ geopotential height (black contours, solid (dash) line for the positive (negative) value with $\mathrm{CI}=1 \mathrm{~m}$ ) and $850 \mathrm{hPa}$ wind (vector, unit: $\mathrm{m} / \mathrm{s}$ ) with red letters "C" and "A" marking the cyclone and anticyclone respectively. The shading in Fig.b and c, indicates the corresponding precipitation anomalies as in Fig.3b with red (blue) for the anomalous precipitation greater (less) than $+(-) 3 \%$. In Fig. a and b, the thick black solid line segments mark the strengthened $500 \mathrm{hPa}$ East Asian trough. 
a)PREC Prec. Comp. on Sm ElNino Idx(1958-2012)
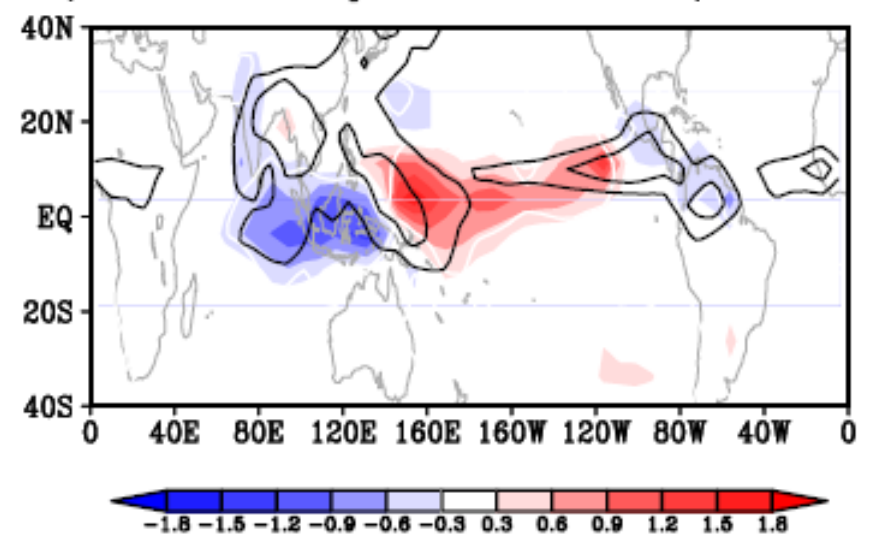

b)CRU Prec. Comp. on Sm ElNino Idx(1958-2012)

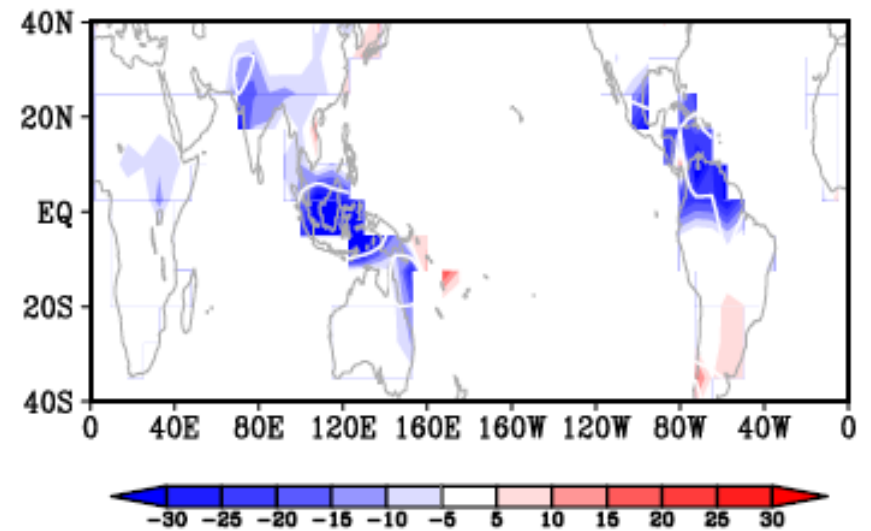

c)GPCP Prec. Comp. on Sm ElNino Idx(1979-2012)

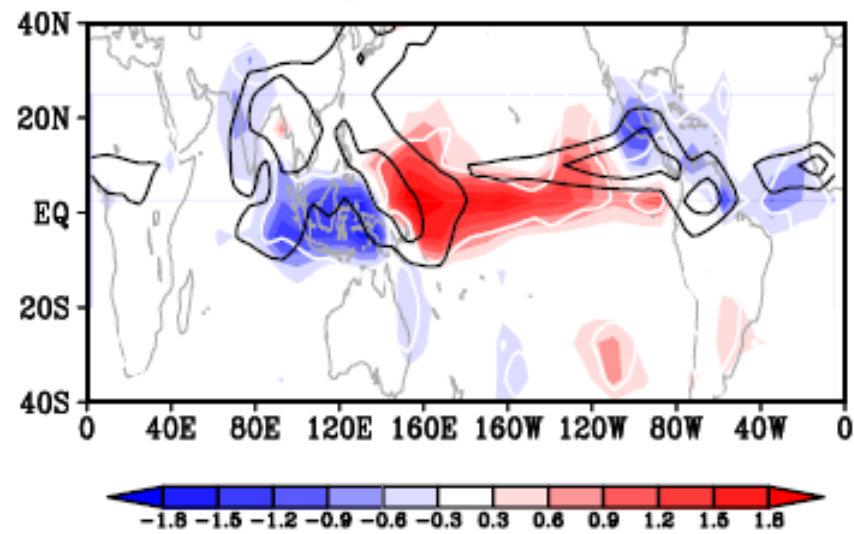

d)NOAA OLR Comp. on Sm EINino Idx(1979-2012)

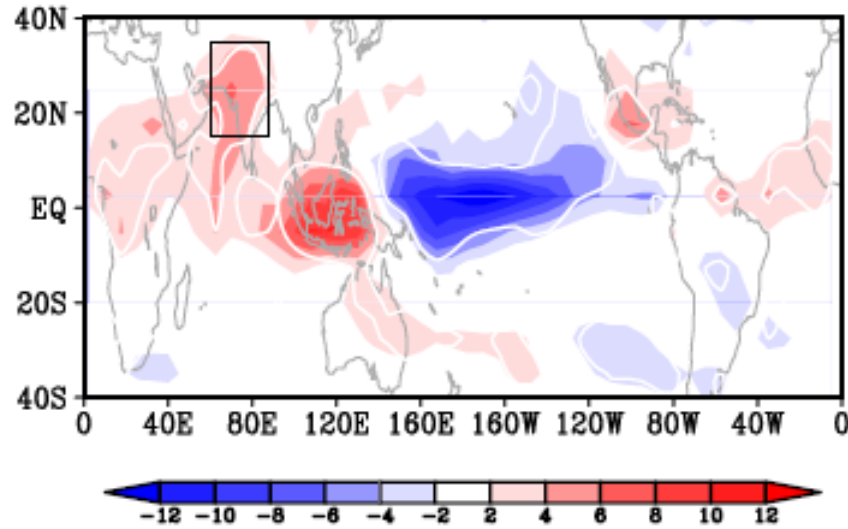

Figure 6 Composite precipitation/OLR anomalies (shaded) from different datasets. a) PREC (CI=0.3 $\mathrm{mm} /$ day) and b) $\mathrm{CRU}$ precipitation anomalies ( $\mathrm{CI}=5 \mathrm{~mm} / \mathrm{month})$ during period of $1958-2012 \mathrm{yr}$. c) GPCP precipitation anomaly $(\mathrm{CI}=0.3 \mathrm{~mm} /$ day $)$ and $\mathrm{d}) \mathrm{OLR}$ anomaly $\left(\mathrm{CI}=2 \mathrm{w} / \mathrm{m}^{2}\right)$ during period of 1979-2012yr. The black contours in upper panels indicate the GPCP climatology precipitation from 1979 to 2012, with contour levels 5 and $8 \mathrm{~mm}$ /day respectively. White contours in the figures denote the $90 \%$ confidence level. 


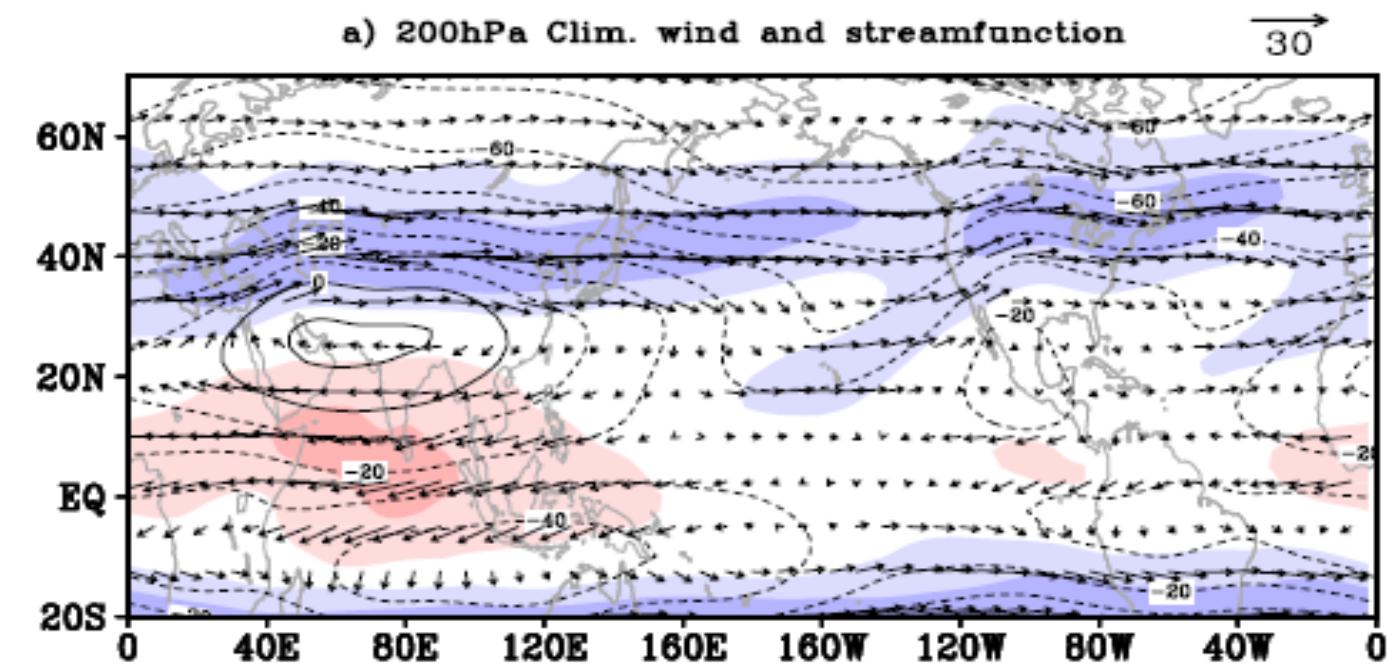

b) $850 \mathrm{hPa}$ Clim. wind and streamfunction

$\overrightarrow{15}$

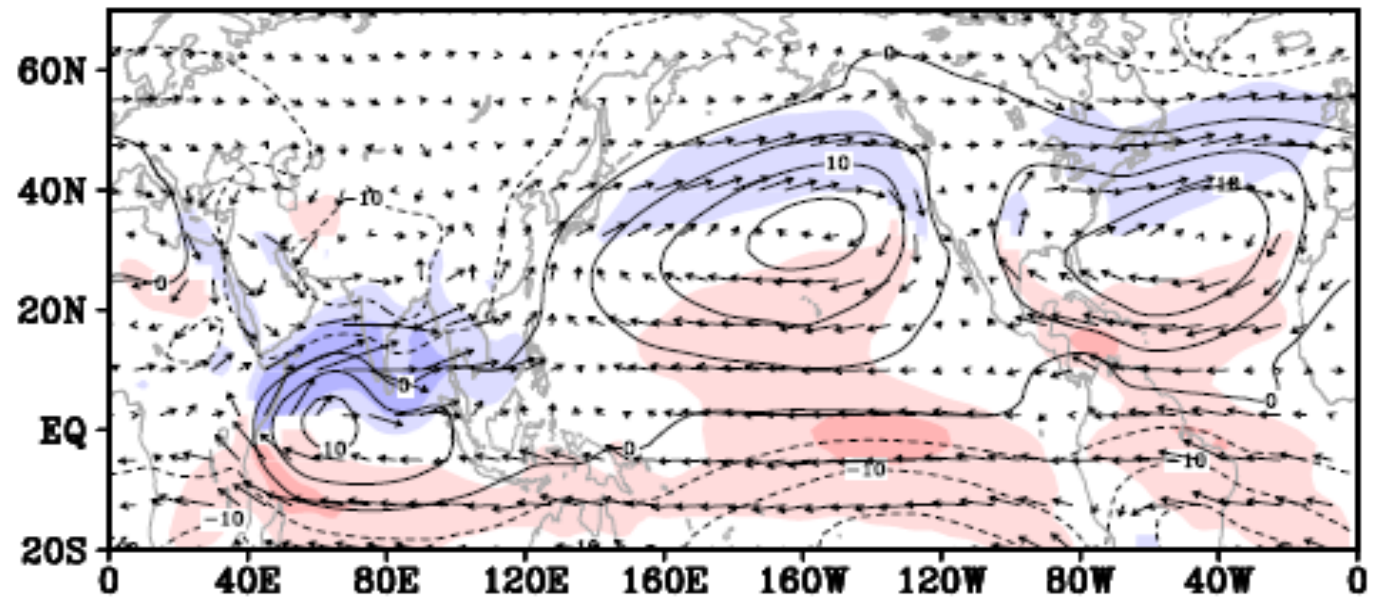

Figure 7 Summer climatology for streamfunction (contours, unit: $10^{6} \mathrm{~m}^{2} \mathrm{~s}^{-1}$ ) and horizontal wind (vector, unit: $\mathrm{m} / \mathrm{s}$ ) at $200 \mathrm{hPa}$ (a) and $850 \mathrm{hPa}(\mathrm{b})$. In the upper / bottom panel, contour interval for streamfunction is $10 \times 10^{6} \mathrm{~m}^{2} \mathrm{~s}^{-1} / 5 \times 10^{6} \mathrm{~m}^{2} \mathrm{~s}^{-1}$. The blue and red shaded in the panels indicate the westerly and easterly wind with scaling at the top right corners, and the light and heavy shading denote the wind speed 10 and $20 \mathrm{~m} / \mathrm{s}$ at $200 \mathrm{hPa}$ and 5 and $10 \mathrm{~m} / \mathrm{s}$ at $850 \mathrm{hPa}$ respectively. 

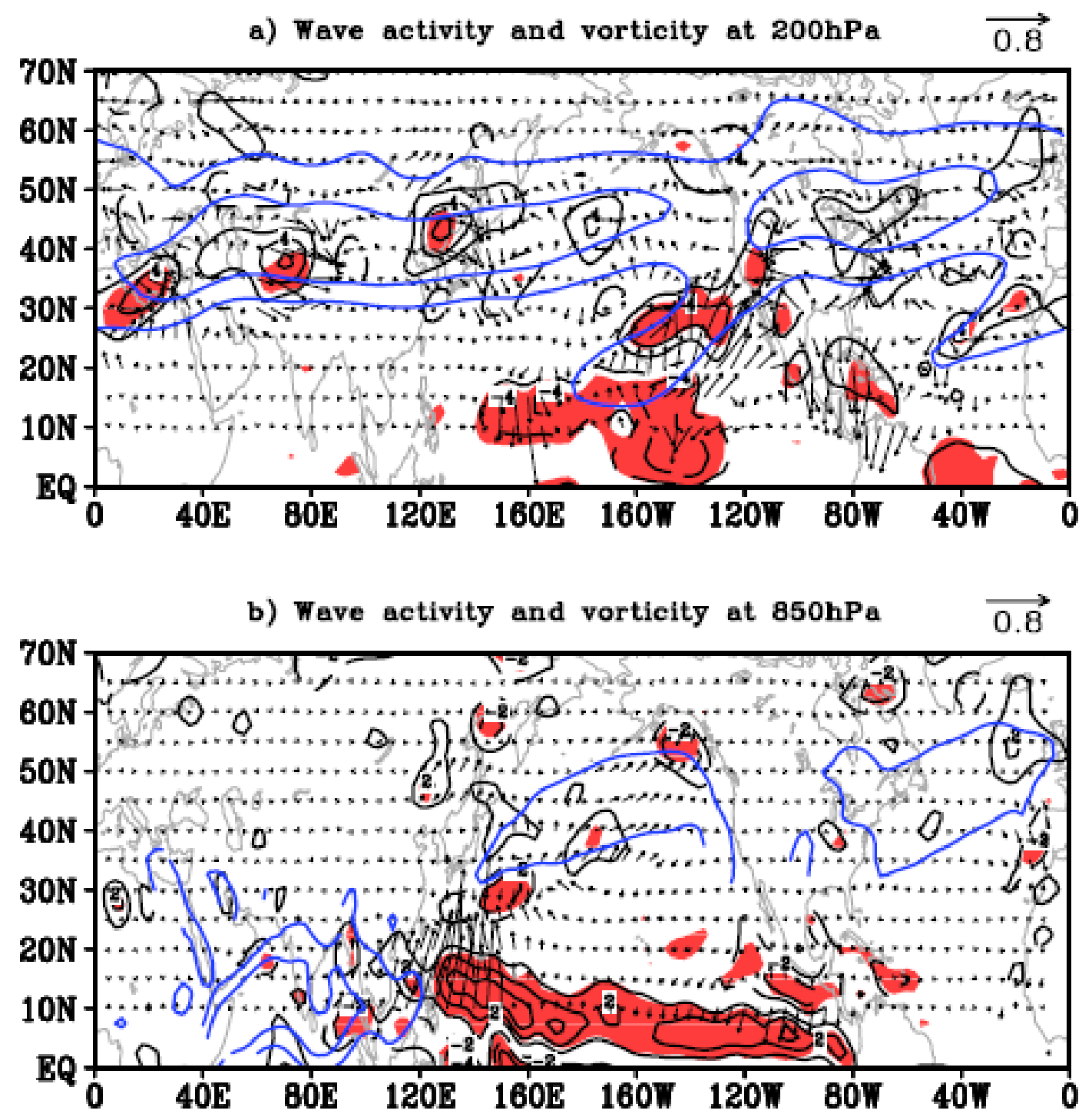

Figure 8 Composite anomalies of vorticity (black contours, unit: $10^{-6} \mathrm{~s}^{-1}$ ) and wave activity flux (vector, unit: $\mathrm{m}^{2} / \mathrm{s}^{2}$ ) at $200 \mathrm{hPa}$ (a) and $850 \mathrm{hPa}$ (b). In upper/bottom panel, contour interval for vorticity is $2 \times 10^{-6} \mathrm{~s}^{-1} / 1 \times 10^{-6} \mathrm{~s}^{-1}$. The superimposed blue contours in the panels denote the climatological westerly wind, with wind speed $10,20 \mathrm{~m} / \mathrm{s}$ at $200 \mathrm{hPa}$ and 5,10 $\mathrm{m} / \mathrm{s}$ at $850 \mathrm{hPa}$ respectively, as indicated by the blue shaded in Fig. $7 \mathrm{a}$ and $\mathrm{b}$. The red shaded in the figures indicates the $90 \%$ confidence level. 
a) Velocity Potential at $200 \mathrm{hPa}$

$\overrightarrow{2.0}$

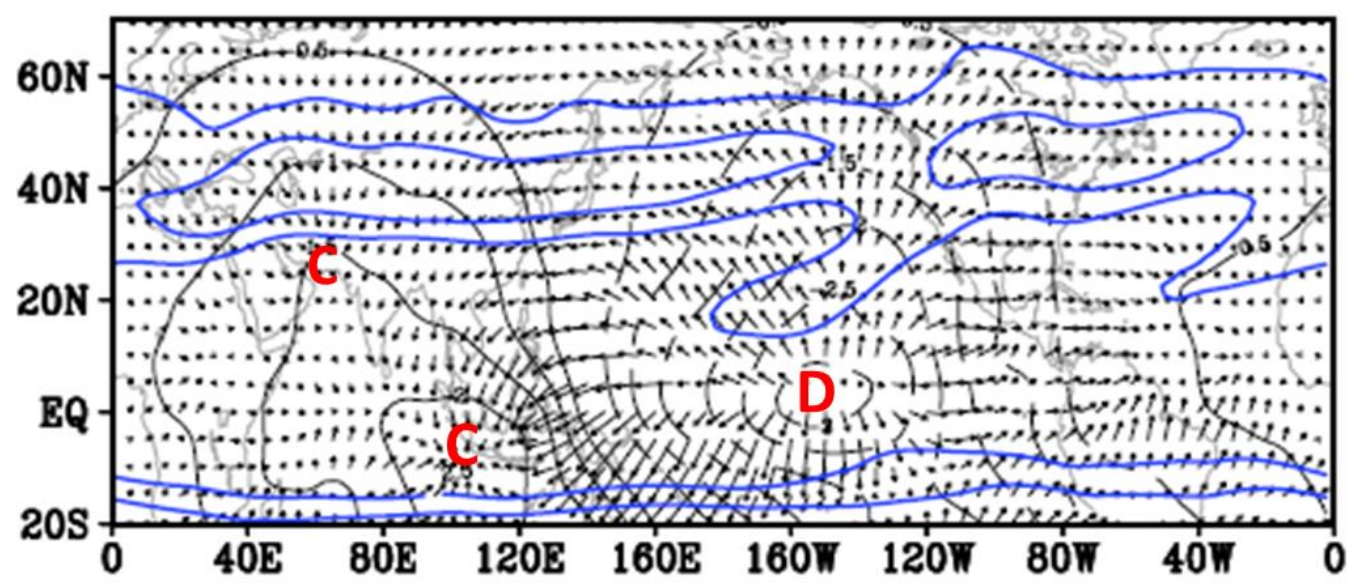

b) Velocity Potential at $850 \mathrm{hPa} \quad \overrightarrow{0.8}$

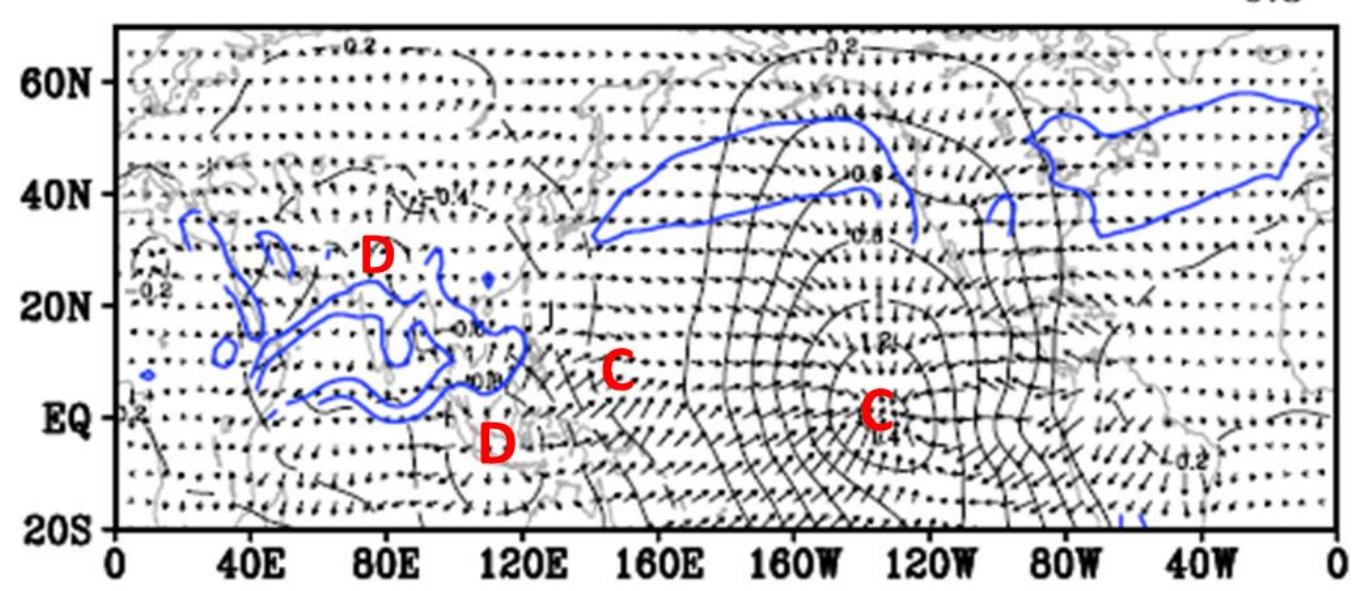

Figure 9 Composite anomalies of velocity potential (black contours, unit: $10^{6} \mathrm{~m}^{2} / \mathrm{s}$ ) and divergence wind (vector, unit: $\mathrm{m} / \mathrm{s}$ ), with climatological westerly wind (blue contours) at $200 \mathrm{hPa}$ (a) and $850 \mathrm{hPa}$ (b). In the upper/ bottom panel, contour interval for velocity potential is $0.5 \times 10^{6} \mathrm{~m}^{2} / \mathrm{s} / 0.2 \times 10^{6} \mathrm{~m}^{2} / \mathrm{s}$. The superimposed blue contours in the panels denote the climatological westerly wind, with wind speed $10,20 \mathrm{~m} / \mathrm{s}$ at $200 \mathrm{hPa}$ and 5,10 $\mathrm{m} / \mathrm{s}$ at $850 \mathrm{hPa}$ respectively. The red letters "C" and " $\mathrm{D}$ " mark the convergence and divergence of the wind purturbation. 
a) PREC Prec. Reg. on Sm PBT Index

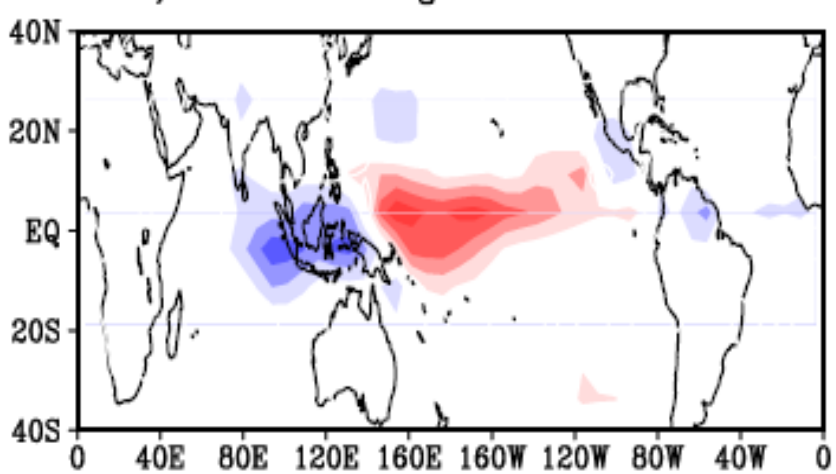

b) PREC Prec. Reg. on Sm IHT Index

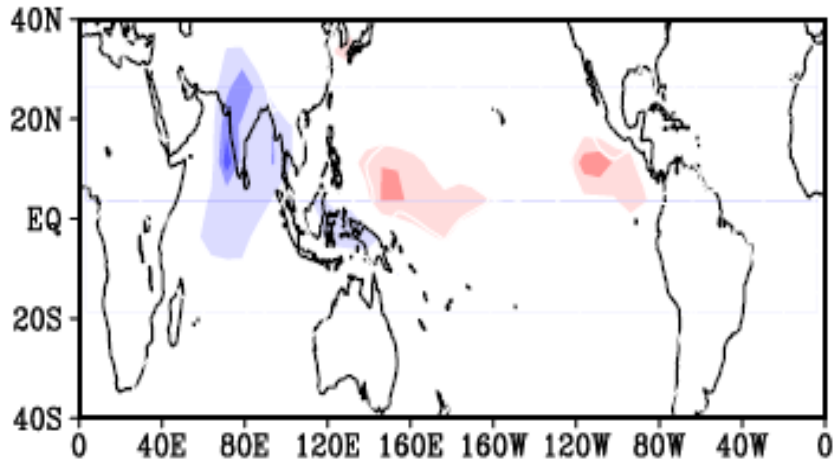

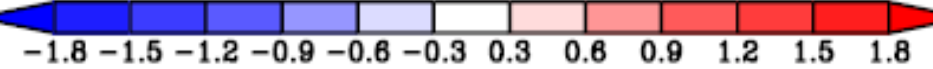

c) Sum. El Nino Heating Indices | Corr $<\mathrm{PHT}$, IHT $>=0.35$

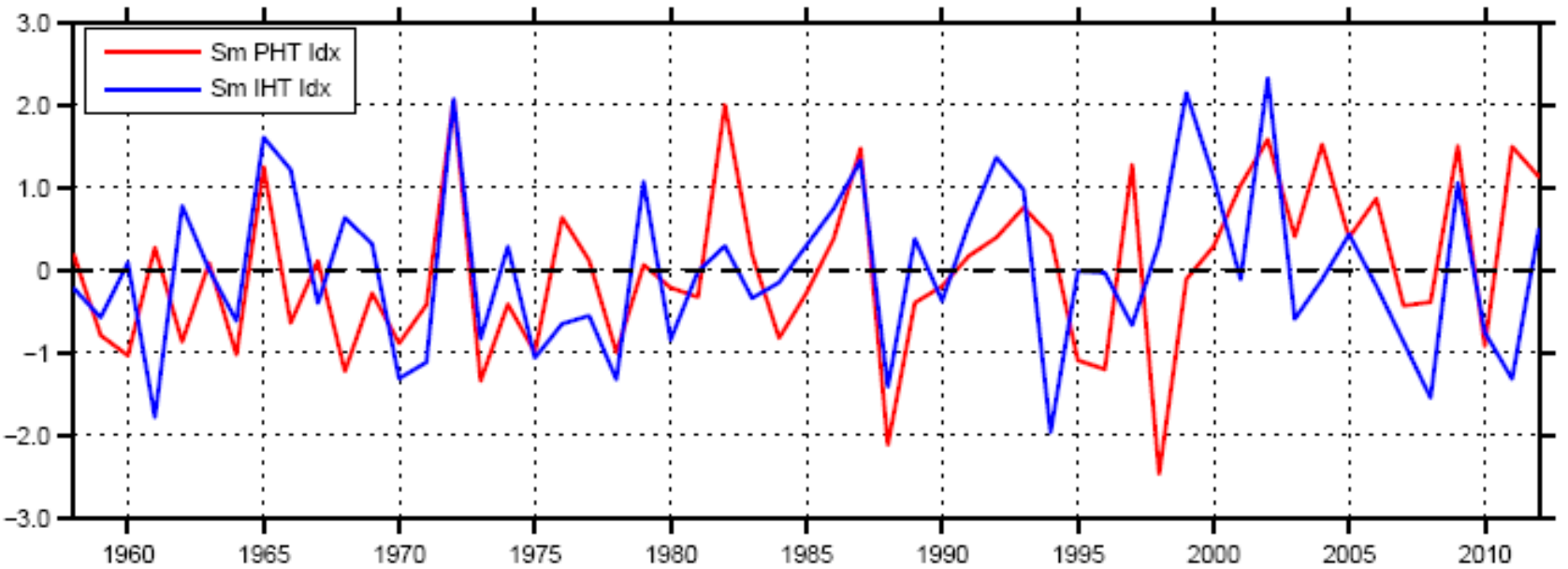

Figure 10 Regressions of PREC precipitation on the summer El Niño-induced heating indices. a) Regression on El Niño-induced direct heating index (PHI) --- the principle component of precipitation EOF1 in the tropical Indo-Pacific $\left(70^{\circ} \mathrm{E} \sim 80^{\circ} \mathrm{W}, 20^{\circ} \mathrm{S} \sim 10^{\circ} \mathrm{N}\right)$. b) Regression on El Niño-induced indirect heating index (IHI) which refer to the domain average of precipitation over Northwest India $\left(60^{\circ} \mathrm{E} \sim 88^{\circ} \mathrm{E}, 15^{\circ} \mathrm{N} \sim 35^{\circ} \mathrm{N}\right)$. c) The corresponding indices are all normalized by their standard deviations with the red (blue) curve for El Niño-induced direct (indirect) heating index PHI (IHI). 
a) Z200 PReg. on Sm PHT Index

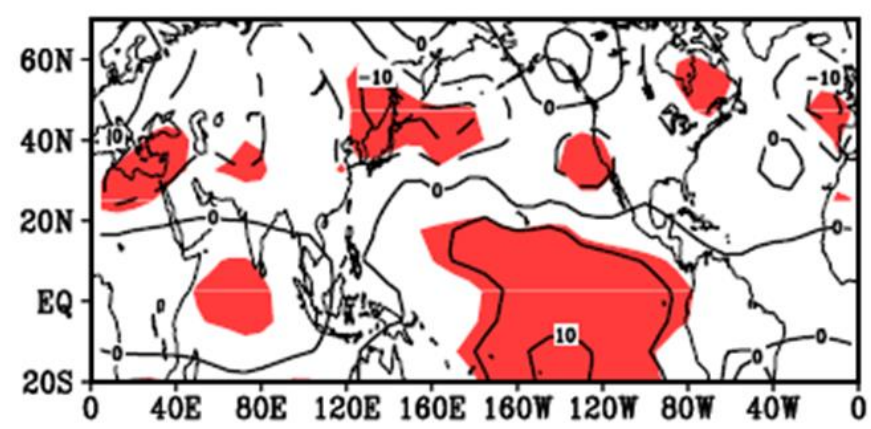

b) UV850/- 5500 PReg. on Sm PET Index
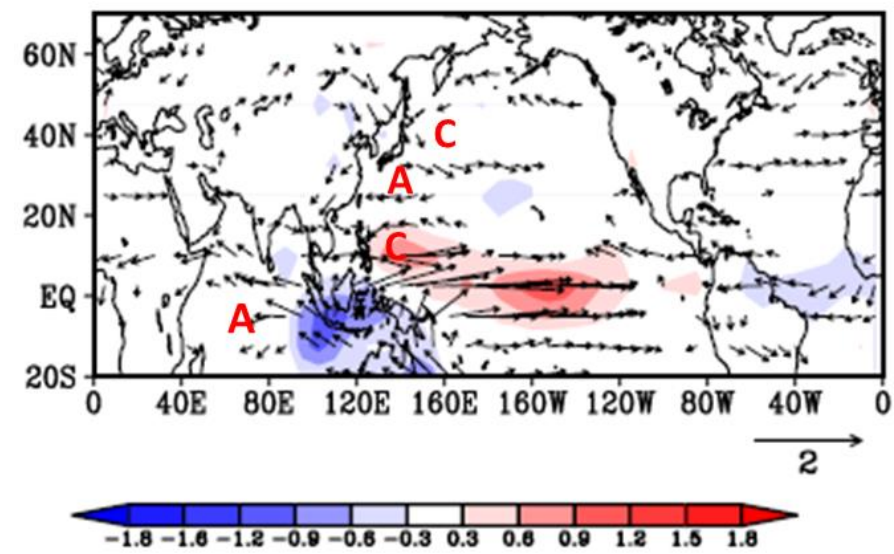

c) Z200 PReg. on Sm IBT Index

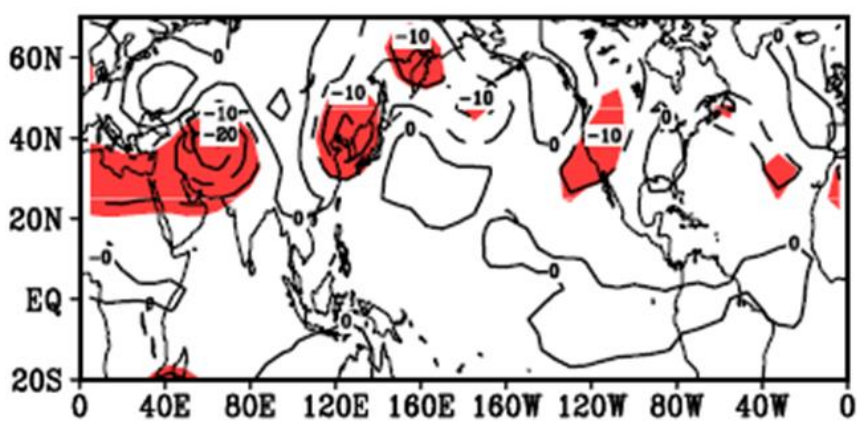

d) UV850/- 5500 PReg. on Sm IHT Index
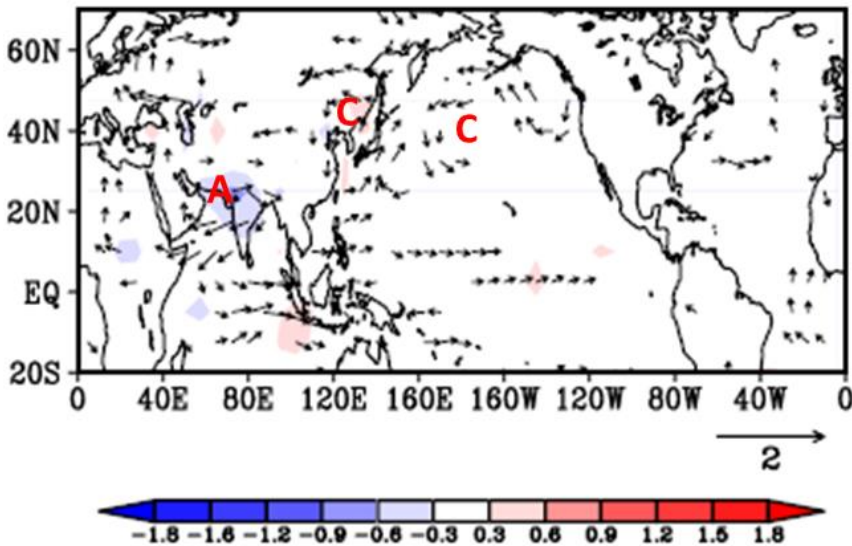

Figure 11 Partial regressions of atmospheric variables in the tropical-northern hemisphere on summer El Niño-induced heating indices with the left panel (Fig. a and b) for the El Niño direct heating index (PHI) and the right panel (Fig. c and d) for the El Niño indirect heating index (IHI). a) and c) $200 \mathrm{hPa}$ geopotential height response with solid (dashed) line for positive (negative) value $(\mathrm{CI}=3 \mathrm{~m})$. The shaded indicates the $90 \%$ confidence level. b) and d) $850 \mathrm{hPa}$ wind (vector, with scaling at the bottom, unit: $\mathrm{m} / \mathrm{s}$ ) and $500 \mathrm{hPa}$ vertical velocity (omega with opposite sign $(-\omega)$, shaded) responses. The small value of wind (magnitude less than $0.2 \mathrm{~m} / \mathrm{s})$ is omitted in figures. The red (blue) shading $\left(\mathrm{CI}=0.3 \times 10^{-2} \mathrm{~Pa} / \mathrm{s}\right.$ ) indicates the air ascending (descending). And, the red letters " $\mathrm{C}$ " and "A" mark the cyclone and anticyclone respectively. 
a) Z200 CRsp to $\mathrm{Sm} \mathrm{HT}(\mathrm{PHT}+\mathrm{IHT} * 0.7)$

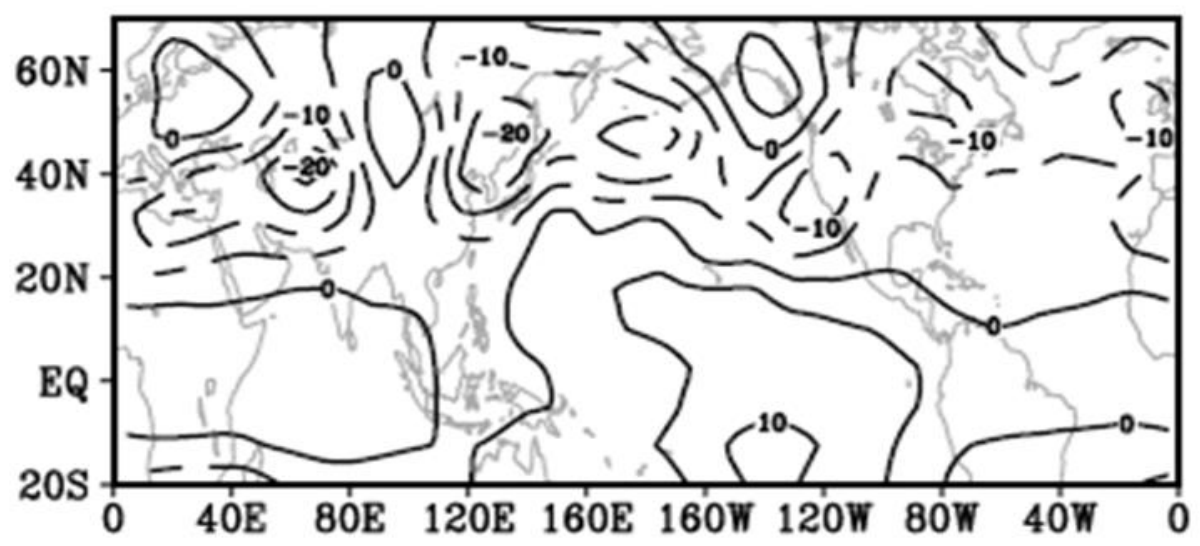

b) uv850/-w500 CRsp to Sm HT(PHT+IHT*0.7)

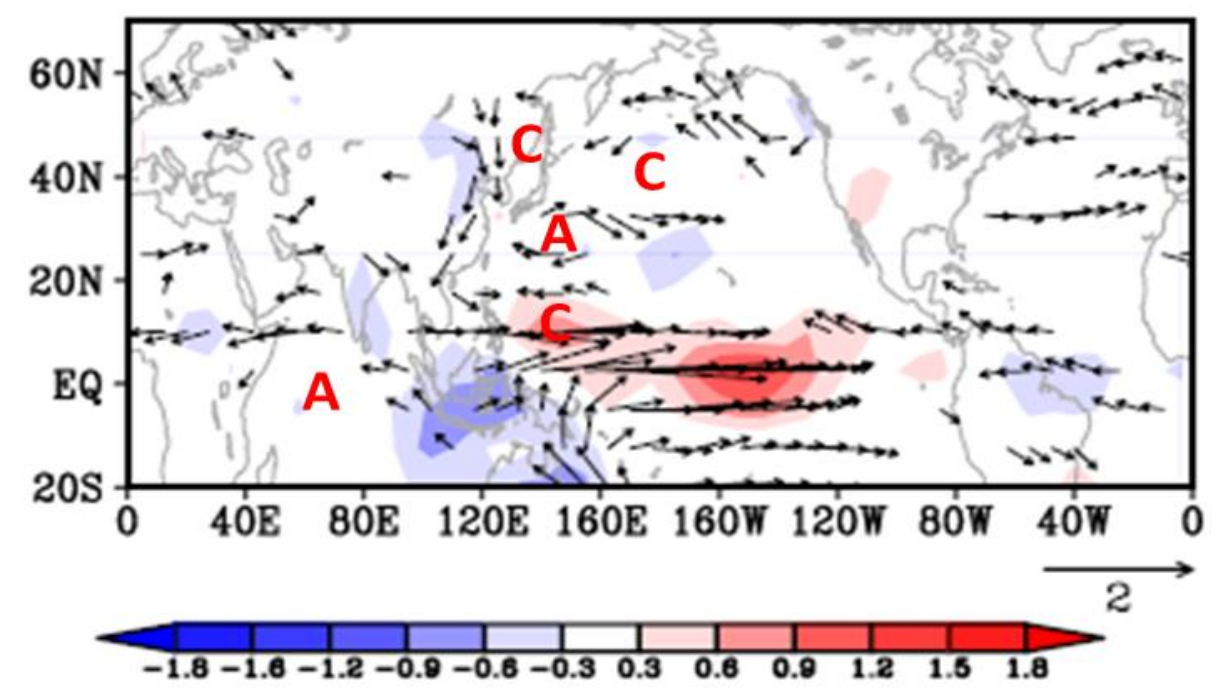

Figure 12 Combined atmospheric response to summer El Niño-induced heatings, which is derived from the linear combination of the partial regressions of atmosphere to the direct heating index (PHI) (Fig.11a, b) and the indirect heating index (IHI) (Fig.11c, d), weighted by 1.0 and 0.7 respectively. a) $200 \mathrm{hPa}$ geopotential height response with solid (dashed) line for positive (negative) value $(\mathrm{CI}=5 \mathrm{~m}) . \mathrm{b}) 850 \mathrm{hPa}$ wind (vector, with scaling at the bottom, unit: $\mathrm{m} / \mathrm{s}$ ) as well as $500 \mathrm{hPa}$ vertical velocity (omega with opposite sign $(-\omega)$, shaded) responses. The small value of the wind (magnitude less than $0.2 \mathrm{~m} / \mathrm{s}$ ) is omitted in the figure. The red (blue) shading $\left(\mathrm{CI}=0.3 \times 10^{-2} \mathrm{~Pa} / \mathrm{s}\right)$ indicates the air ascending (descending). And, the red letters "C" and "A" mark the cyclone and anticyclone respectively. 


\section{Mechanism of Summer El Niño influence}

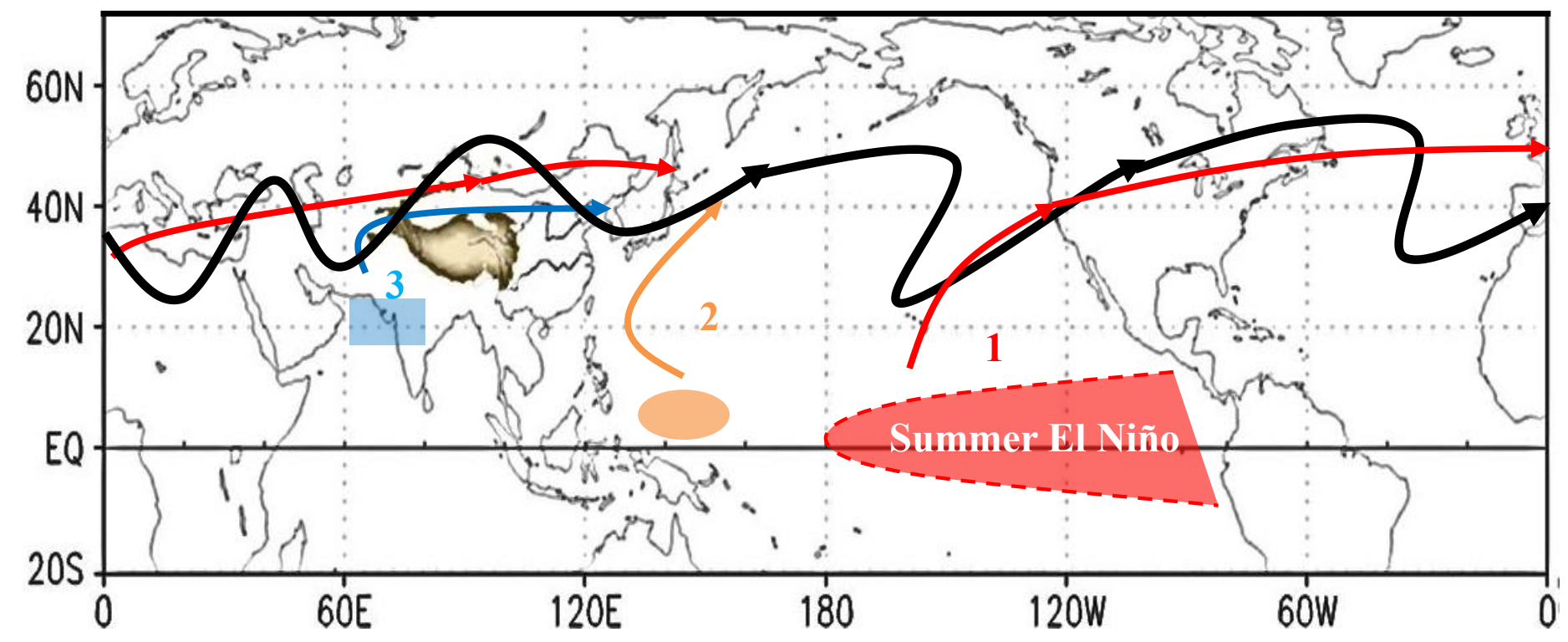

Figure 13 Schematic figure showing the summer El Niño influence on atmosphere in three ways. The first path refers to the El Niño-induced vertical perturbation over the eastern-central tropical Pacific into the subtropical jet, exciting the wave propagation downstream to East Asia (as indicated by the red curve). The second is the El Niño-induced convective activity over the Maritime Continent, generating the low-level wave propagation along the East Asia coast (as indicated by the orange curve). And the third is the El Niño-induced indirect suppressed heating over Northwest India, triggering the perturbation in the subtropical jet and wave propagation to the downstream of East Asia (as indicated by the curve). 